\title{
Physicochemical Characterization of a Crude Anthocyanin Extract from the Fruits of Jussara (Euterpe edulis Martius): Potential for Food and Pharmaceutical Applications
}

\author{
Laura I. L. Favaro, ${ }^{a}$ Victor M. Balcão, ${ }^{a, b}$ Liliam K. H. Rocha,${ }^{a}$ Erica C. Silva, ${ }^{a}$ \\ José M. Oliveira Jr., ${ }^{a}$ Marta M. D. C. Vila ${ }^{*, a}$ and Matthieu Tubino ${ }^{*, c}$ \\ ${ }^{a}$ Laboratório de Biofilmes e Bacteriófagos (PhageLab), Universidade de Sorocaba, \\ 18023-000 Sorocaba-SP, Brazil \\ ${ }^{b}$ Centre of Biological Engineering (CEB), University of Minho, 4710-057 Braga, Portugal
}

'Instituto de Química, Universidade Estadual de Campinas, 13083-970 Campinas-SP, Brazil

\begin{abstract}
In the present research effort, production of a crude anthocyanin extract from the fruits of jussara (Euterpe edulis Martius) was pursued. The physico-chemical characteristics of the crude anthocyanin extracts were evaluated via Fourier transform infrared spectrophotometry, $\mathrm{X}$-ray diffraction, $\mathrm{X}$-ray fluorescence, computed tomography via X-ray transmission, UV-Vis spectrophotometric scannings, differential scanning calorimetry, antimicrobial activity, anthocyanin quantification, total phenolic content, thin layer chromatography for sugars and pigments, free radical 2,2-diphenyl-1-picryl-hydrazil (DPPH) scavenging activity and antioxidant activity via the molybdenum phosphate complex. The results gathered suggest that the crude anthocyanin extracts had both obvious antioxidant activity and radical scavenging effects with the DPPH assay, and light antibacterial activity against Staphylococcus aureus, further suggesting that this crude pigment extract might be a valuable addition for either food or pharmaceutical applications.
\end{abstract}

Keywords: anthocyanin, crude anthocyanin extract, Euterpe edulis Martius, jussara

\section{Introduction}

The fruit of the Euterpe edulis palm has the form of globose berries and are wealthy in anthocyanins. ${ }^{1}$ Anthocyanins are glycosylated polyhydroxy and polymethoxy derivatives of 2-phenylbenzopyrylium (flavylium) salt, which are natural pigments widely distributed in nature, containing conjugated double bonds responsible for absorption of light around $500 \mathrm{~nm}$ causing the typical color of these pigments. ${ }^{2,3}$ Anthocyanins (Greek anthos: flower and kianos: blue) confer blue, purple and red color to many fruits, flowers and vegetables. ${ }^{4,5}$ Beside this, anthocyanins have pharmacological relevance and therapeutic properties ${ }^{6}$ with capacity to reduce incidence of cardiovascular disease, diabetes mellitus and cancer. ${ }^{5}$ These effects are thought to be related with high antioxidant capacity and inhibition of DNA damage in cells. ${ }^{7}$ The biological activity of anthocyanins occurs through the donation of electrons or hydrogen atoms from its hydroxyl to free radical. ${ }^{8}$ High intakes of anthocyanins

*e-mail: marta.vila@prof.uniso.br; tubino@iqm.unicamp.br can be achieved in fruit as blueberries, blackberries, raspberries, strawberries, red grapes, saskatoon berries ${ }^{5}$ and acerola fruit. ${ }^{9}$ Another good source of anthocyanins are purple sweet potato and red cabbage. ${ }^{10}$ The diversity and quantity of compounds present in tropical fruit have attracted the interest of science and industry, especially due to their source of bioactive substances with antioxidant capacities $^{6}$ such as açaí and jussara fruits. ${ }^{11,12}$ The jussara fruit is obtained from a species of palm (Euterpe edulis) belonging to Arecaceae family. The jussara palm is widely distributed in the Brazilian Atlantic Forest and produces edible palm hearts and spherical fruits denominated jussara. ${ }^{13,14}$ Jussara is known as a "super fruit" together with other fruits such as açaí, pomegranate, blueberry and goji berry. The term is an expression used to refer, mostly, to fruits with a high nutritional value, great antioxidant capacity, energetic power, immune-boosting and antiaging properties. These bioactivities are mainly attributed to the substantial amounts of phytochemicals in the fruit, such as polyphenols, notably anthocyanins, polysaccharides and phenolic acids. ${ }^{1,15,16}$ Anthocyanins are among the main compounds related to the great free radical-scavenging 
capacities of jussara fruits, which present a positive significant correlation with antioxidant capacity of these fruits. ${ }^{16}$ However, the isolated anthocyanins are highly instable and very susceptible to degradation. The stability of anthocyanins is influenced by many factors such as their structure, concentration, $\mathrm{pH}$, light, oxygen, temperature, solvents and presence of enzymes, other flavonoids, metallic ions and proteins. ${ }^{6,10}$ Thus, extraction, purification and concentration processes of the natural compounds are important steps to obtain stable extracts, which can be utilized in food, pharmaceuticals or cosmetics products. This way, the extraction and the characterization of this compound in the studied fruit is justified. The objective of this research was to determine the physicochemical characteristics and antimicrobial activity of the anthocyanin extract obtained from jussara fruit. Hence, production of a crude anthocyanin extract from the fruits of jussara was pursued in this research as a potentially valuable bioactive extract, together with an physico-chemical characterization of the crude extracts. The physico-chemical characteristics of the crude anthocyanin extracts produced were evaluated in detail, via infrared spectrophotometry with Fourier transform (FTIR), X-ray diffraction analyses (XRD), X-ray fluorescence analyses (XRF), X-ray tomographic analysis (XRT), UV-Vis scanning, thermal analyses via differential scanning calorimetry (DSC), anthocyanin quantification, antimicrobial activity, determination of total phenolic content, thin layer chromatography (TLC) for sugars and pigments, and antioxidant and free radical 2,2-diphenyl1-picryl-hydrazil (DPPH) scavenging activities.

\section{Experimental}

\section{Chemicals}

All reagents used were of analytical grade or better, and were used without further purification. Tap water was purified in a Master System All (model MS2000, Gehaka, São Paulo, SP, Brazil) to a final resistivity of ca. $18.18 \mathrm{M} \Omega \mathrm{cm}$ and conductivity of $0.05 \mu \mathrm{S} \mathrm{cm}^{-1}$. DPPH (2,2-diphenyl-1-picrylhydrazyl) (ref. SIGMA D9132-1G), gallic acid (3,4,5-trihydroxybenzoic acid, ref. SIGMA G7384-100G), rutin (ref. SIGMA R514350G) and quercetin (3,3,4,5,7-pentahydroxyflavone, ref. SIGMA Q0125-10G) were purchased from SigmaAldrich (St. Louis, MO, USA). The antibiotic solution (penicillin (10000 UI mL $\left.\mathrm{mL}^{-1}\right) /$ streptomycin $\left(10 \mathrm{mg} \mathrm{mL}^{-1}\right)$ ) was acquired from Vitrocell Embriolife, Comércio de Produtos para Laboratório Ltda. (Campinas, SP, Brazil). Ascorbic acid was acquired from CAQ, Casa da Química Ltda. (Diadema, SP, Brazil).

\section{Biological materials}

The fruits from Euterpe edulis Martius were collected from a jussara palm tree in October 2016 from the São Domingos farm, located in Jaguariúna (São Paulo, SP, Brazil). The bacterial strains utilized in the antimicrobial assays were Staphylococcus aureus CCCD-S007, Pseudomonas aeruginosa CCCD-P004, and Escherichia coli CCCD-E003, supplied by CEFAR Diagnóstica (Jurubatuba, SP, Brazil). The microbiological growth media utilized were BHI (brain heart infusion) from HiMedia Laboratories (Mumbai, India) and bacteriological agar from Prodimol Biotecnologia S.A. (São Paulo, SP, Brazil).

\section{Analytical equipment}

FTIR spectra were gathered in a Fourier transform infrared spectrophotometer from Shimadzu (model IR Affinity-1S, Kyoto, Japan) with an ATR (attenuated total reflectance) module. X-ray diffractograms were gathered in an X-ray diffractometer (XRD) from Shimadzu (model XRD7000, Kyoto, Japan). All spectrophotometric analyses were carried out in a UV-Vis spectrophotometer from Lengguang Technology Co. (model Gold Spectrumlab 53, Shanghai, China). Thermal analyses were pursued by differential scanning calorimetry (DSC) using a differential scanning microcalorimeter from Shimadzu (model DSC-60, Shimadzu, Kyoto, Japan). A computed tomographer via X-ray transmission from Bruker microCT (model SkyScan 1174, Kontich, Belgium), and an X-ray fluorescence spectrometer (EDXRF) from Amptek Inc. (model XRF Experimenter's Kit, Bedford, MA, USA) were utilized in all non-destructive analyses, for gathering tomographic images of the fruit of jussara microstructure and its elemental composition. The analysis software utilized for processing the tomographic images were CTVox $^{\text {TM }}$ (version 2.6.0 r908-64bit, from Bruker microCT), $\mathrm{CTan}^{\mathrm{TM}}$ (version 1.13.5.1-64bit, from Bruker microCT) and CTvol (version 2.2.3.0-64bit, from Bruker microCT). All refractive index measurements were performed in an Abbe refractometer (type WYA-2WAJ) from Shanghai YiCe Apparatus \& Equipment co. Ltd. (Shanghai, China).

\section{Methods}

Extraction of anthocyanin pigments from the fruits of jussara

For producing the crude anthocyanin extracts, $100 \mathrm{~g}$ of whole fruits were placed in contact with $100 \mathrm{~mL}$ ethanol $(95 \% \mathrm{v} / \mathrm{v})$, in a thermostated water bath set at $55^{\circ} \mathrm{C}$, during a period of $30 \mathrm{~min}$. After this time period, the resulting 
ethanolic extract was filtered through paper filter directly into glass Petri plates, which were then placed in an incubation chamber set at room temperature for allowing ethanol removal by evaporation. Following drying, the crude anthocyanin extract was carefully collected into a dark-brown glass flask, duly weighed and kept at $-18^{\circ} \mathrm{C}$ until use.

\section{Refractive index analyses}

The sugar content of the crude anthocyanin extract produced was determined via refractive index measurements using an Abbe refractometer (type WYA-2WAJ). For these determinations, an aqueous solution of crude extract was prepared (100 $\mathrm{mg}_{\text {crude anthocyanin extract }} \mathrm{mL}_{\text {ultrapure water }}^{-1}$ ) and a drop was placed onto the crystal prism of the refractometer. All determinations were carried out at $18{ }^{\circ} \mathrm{C}$.

\section{Quantification of anthocyanins in the crude anthocyanin extract}

The anthocyanin content of the crude extracts was determined spectrophotometrically via the differential $\mathrm{pH}$ method, in triplicate, according to the procedure described by the Association of Official Analytical Chemists (AOAC). ${ }^{17-19}$ Samples of the crude anthocyanin extract produced from the whole jussara fruits were weighed separately (viz. 52, 51 and $51 \mathrm{mg}$ ), introduced into $25 \mathrm{~mL}$ volumetric flasks, and duly added with ultrapure water up to $25 \mathrm{~mL}$. $500 \mu \mathrm{L}$ of each solution were then pipetted and poured into $5 \mathrm{~mL}$ volumetric flasks followed by completion of the volume with a $\mathrm{KCl} / \mathrm{HCl}$ buffer solution of $\mathrm{pH} 1.0$. The same procedure was followed for sodium acetate buffer solution of $\mathrm{pH} 4.5$. All solutions in the $5 \mathrm{~mL}$ volumetric flasks underwent then spectrophotometric readings for registering their absorbances at 520 and $700 \mathrm{~nm}$. The concentration of anthocyanin pigment in the crude extract could then be calculated using equation 1 .

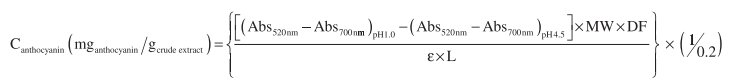

where Abs is the absorbance, MW is the molecular weight of cyanidin-3-glycoside $\left(449.2 \mathrm{~g} \mathrm{~mol}^{-1}\right)$, DF is the dilution factor employed, $\varepsilon$ is the molar extinction coefficient of cyanidin-3-glucoside $\left(26900 \mathrm{~L} \mathrm{~mol}^{-1} \mathrm{~cm}^{-1}\right)$, $\mathrm{L}$ is the light path in the quartz cuvette $(1.0 \mathrm{~cm})$, and 0.2 is the concentration of the crude anthocyanin extract $\left(0.2 \mathrm{mg} \mathrm{mL}^{-1}\right)$.

Determination of the total phenolic content of the crude anthocyanin extracts via the Folin-Ciocalteau method

For determining the total phenolic content of the crude anthocyanin extracts, the procedure described by Kiralp and Toppare ${ }^{20}$ was followed, with slight modifications: (i) preparation of a gallic acid stock-solution: to a $100 \mathrm{~mL}$ volumetric flask, $500 \mathrm{mg}$ of dry gallic acid were poured and dissolved with $10 \mathrm{~mL}$ ethanol, and the resulting solution was further diluted to $100 \mathrm{~mL}$ with ultrapure water; (ii) preparation of a saturated sodium carbonate solution: fifty grams of anhydrous $\mathrm{Na}_{2} \mathrm{CO}_{3}$ were dissolved in $250 \mathrm{~mL}$ ultrapure water, and the resulting solution was heated up to $100{ }^{\circ} \mathrm{C}$. After cooling down, a spatula tip of $\mathrm{Na}_{2} \mathrm{CO}_{3}$ crystals were added and, after $24 \mathrm{~h}$, the solution was filtered through a filter paper with average pore size of $14 \mu \mathrm{m}$; (iii) preparation of a calibration curve: for preparing a calibration curve, $0,100,200,400,600,800$ and $1000 \mu \mathrm{L}$ of the stocksolution of gallic acid were poured into $10 \mathrm{~mL}$ volumetric flasks and diluted up to $10 \mathrm{~mL}$ with ultrapure water. From each calibration solution, $20 \mu \mathrm{L}$ of sample solution, or blank (water), were pipetted into separate (disposable) cuvettes and, to each cuvette, $1580 \mu \mathrm{L}$ of ultrapure water were added followed by addition of $100 \mu \mathrm{L}$ of the FolinCiocalteau reagent. The contents of the several cuvettes were then duly homogenized by covering the cuvettes and inverting them several times. After $5 \mathrm{~min}, 300 \mu \mathrm{L}$ of the saturated $\mathrm{Na}_{2} \mathrm{CO}_{3}$ solution were added to each cuvette and the resulting solutions duly homogenized as described above. All cuvettes were then maintained at $20{ }^{\circ} \mathrm{C}$ during $2 \mathrm{~h}$ and, after this period, the absorbance of each solution was determined at $765 \mathrm{~nm}$. For the crude extract samples, $20 \mu \mathrm{L}$ of a $20 \mathrm{mg}_{\text {extract }} \mathrm{mL}_{\text {ultrapure water }}^{-1}$ solution were added as for the calibration solutions, and the procedure was repeated for reading the absorbance at $765 \mathrm{~nm}$. The total phenolic content (TPC) was then determined as $\mathrm{mg}_{\text {gallic acid equivalents }} \mathrm{g}^{-1}$ extract $\left(\mathrm{mg}_{\mathrm{GAE}} \mathrm{g}^{-1}\right.$ extract $)$ for the crude anthocyanin extract samples using equation 2 below.

$\operatorname{TPC}\left(\mathrm{mg}_{\mathrm{GAE}} g_{\text {extract }}^{-1}\right)=\frac{\left(\Phi\left(\mu \mathrm{g}_{\mathrm{GAB}} \mathrm{mL}^{-1}\right) \times\left(0.001 \mathrm{mg} \mu \mathrm{g}^{-1}\right) \times \mathrm{V}_{\text {sanple }}(\mathrm{mL}) \times \text { Dilution factor }\right)}{\mathrm{m}_{\text {extract }}(\mathrm{mg})}$

where $\Phi$ is the concentration of gallic acid equivalents as determined by interpolation of the sample absorbances in the calibration curve produced.

\section{FTIR analyses}

The infrared spectrum of the crude anthocyanin extract was gathered using an FTIR spectrophotometer (ATR) from Shimadzu (model IR Affinity-1S, Kyoto, Japan), in the wavenumber range from 4000 to $400 \mathrm{~cm}^{-1}$, with a resolution of $4 \mathrm{~cm}^{-1}$, and using Happ-Genzel apodization.

\section{XRD analyses}

$\mathrm{X}$-ray diffractograms of the crude anthocyanin extracts were gathered in an X-ray diffractometer (XRD) from Shimadzu (model XRD7000, Kyoto, Japan), using 
$\mathrm{X}$-ray radiation from a copper lamp with radiation $\mathrm{K} \alpha$ $(\lambda=1.5418 \AA)$ filtered through a $\mathrm{Cu}$ target. The X-ray scanning was performed at diffraction angles of $2 \theta$ (from $5^{\circ}$ to $90^{\circ}$, with increments of 0.02 degrees and rate of $2^{\circ} \mathrm{min}^{-1}$ ), with a voltage of $40 \mathrm{kV}$, electric current intensity of $30 \mathrm{~mA}$, and X-ray power of $3 \mathrm{~kW}$.

Thermal analyses via differential scanning calorimetry (DSC)

Thermal characterization of the crude anthocyanin extract was accomplished via DSC, following the procedure described by Glasser et al. ${ }^{21}$ For the calorimetric assays, samples (7.6 mg of crude anthocyanin extract) were weighed directly into the interior of high-pressure aluminium pans, and duly sealed by pressure. A reference aluminum pan was also prepared by simply sealing air inside an empty case. The samples were then subjected to a linear temperature increase from ca. 25 up to $300{ }^{\circ} \mathrm{C}$, at a constant heating rate of $10{ }^{\circ} \mathrm{C} \mathrm{min}^{-1}$, under an inert atmosphere maintained with a constant flow of nitrogen of $10 \mathrm{~mL} \mathrm{~min}^{-1}$, during which the amount of heat absorbed by the hydrogel samples was recorded. During the analyses, data (heat absorption) was gathered at a sampling rate of 0.2 s per data point.

Evaluation of antimicrobial activity of the crude anthocyanin extracts via the agar-diffusion method

The potential antimicrobial efficacy of the crude anthocyanin extract was determined via the agar diffusion technique for susceptibility to antimicrobials described by Bauer et al. ${ }^{22}$ and Jorgensen and Ferraro, ${ }^{23}$ as well as according to the standards of the Clinical and Laboratory Standards Institute (CLSI). ${ }^{24,25}$ The assays were carried out in duplicate, using a strain of Staphylococcus aureus CCCD-S007, a strain of Pseudomonas aeruginosa CCCD-P004, and a strain of Escherichia coli CCCD-E003 (maintained at $-80{ }^{\circ} \mathrm{C}$ in culture medium with $40 \%$ (v/v) glycerol). For revival of the bacterial strains, these were suspended, individually, in $50 \mathrm{~mL}$ of $\mathrm{BHI}$ nutritive broth and incubated in an orbital shaker at $100 \mathrm{rpm}$ and $37^{\circ} \mathrm{C}$ during $24 \mathrm{~h}$. Aqueous crude anthocyanin extract solutions were prepared with concentrations of $20 \mathrm{mg}_{\text {crude anthocyanin extract }} \mathrm{mL}_{\text {sterile ultrapure water }}^{-1}$. The bacterial strains were, initially, inoculated in BHI nutritive broth and maintained at $37 \pm 0.5{ }^{\circ} \mathrm{C}$ during $24 \mathrm{~h}$, to allow bacterial growth. All bacterial cultures were standardized at 0.5 in the McFarland scale, containing ca. $1.5 \times 10^{8}$ colony-forming unit $(\mathrm{CFU}) \mathrm{mL}^{-1}$, by performing dilutions in sterile BHI broth until attaining a turbidity equivalent to the 0.5 standard in the McFarland scale. Following this time period, the bacterial cultures were inoculated by spreading on the surface of two Petri plates containing solidified TSA (tryptic soy agar) as culture medium, and the crude extract samples to be tested were then immediately applied on the inoculated medium, in duplicate, with the aid of sterile tweezers near a Bunsen burner flame (sterile filter paper discs (ca. $7.0 \mathrm{~mm}$ in diameter) impregnated by plunging in the crude anthocyanin extract solution). As can be seen in Figure 1, section 1 was applied with a disc impregnated with antibiotic solution (penicillin (10000 UI mL $\left.\mathrm{mL}^{-1}\right) /$ streptomycin $\left(10 \mathrm{mg} \mathrm{mL}^{-1}\right)$ ) functioning as positive standard of inhibition, section 2 was applied with a disc impregnated with sterile ultrapure water functioning as negative standard of inhibition, and section 3 was applied with a disc impregnated with the crude anthocyanin extract solution. The Petri plates were then allowed to dry, inverted and incubated under aerobic conditions at $36 \pm 0.5{ }^{\circ} \mathrm{C}$ during $24 \mathrm{~h}$. After this time period, the plates were visually inspected for observation (or not) of any growth inhibition halos.

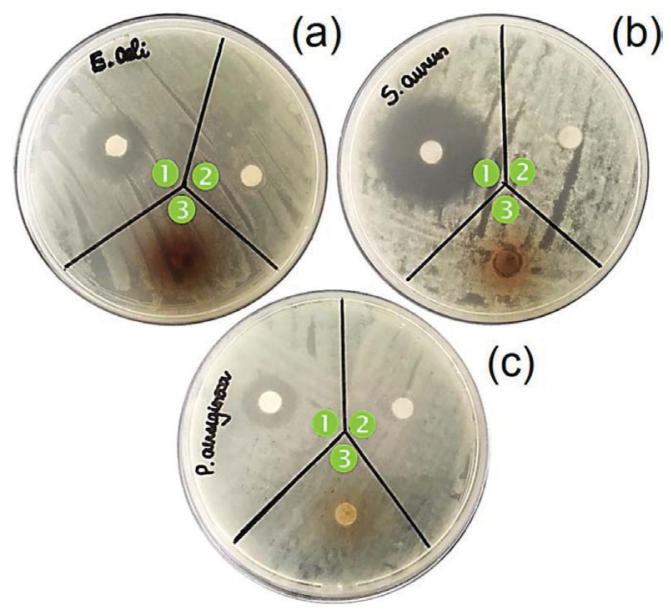

Figure 1. Results obtained from the antimicrobial activity assays of the crude anthocyanin extract against (a) Escherichia coli; (b) Staphylococcus aureus or (c) Pseudomonas aeruginosa. Section 1 (positive standard of inhibition): antibiotic solution (penicillin (10000 UI mL-1)/streptomycin (10 $\left.\mathrm{mg} \mathrm{mL}^{-1}\right)$; section 2 (negative standard of inhibition): sterile ultrapure water; section 3 (sample): crude anthocyanin extract solution.

Evaluation of the antioxidant activity via the molybdenum phosphate reaction and free radical scavenging activity via the DPPH method

\section{(i) Molybdenum phosphate reaction}

Described by Prieto et al. ${ }^{26}$ this technique is based on the reduction of molybdenum(VI) to molybdenum(V) in the presence of certain substances with antioxidant capabilities, with formation of a green complex between phosphate and molybdenum(V) at acid $\mathrm{pH}$, which is determined spectrophotometrically at $695 \mathrm{~nm}$. The complex produced 
possesses a yellow coloration, which becomes green as it is being reduced. A reagent is prepared containing sodium phosphate $(386.4 \mathrm{mg})$, ammonium molybdate $(494.3 \mathrm{mg})$ and commercial sulfuric acid $(3300 \mu \mathrm{L})$ with the volume made up to $100 \mathrm{~mL}$ with ultrapure water. For the assay, $300 \mu \mathrm{L}$ of the crude anthocyanin extract solution $\left(100 \mu \mathrm{g}_{\text {crude anthocyanin extract }} \mathrm{mL}_{\text {ultrapure water }}^{-1}\right)$ were added to $3000 \mu \mathrm{L}$ of the reagent. The same procedure was followed for ascorbic acid (100 $\mu \mathrm{g}_{\text {ascorbic acid }} \mathrm{mL}_{\text {ultrapure water }}^{-1}$ ), since it will be utilized as standard. For the blank, $300 \mu \mathrm{L}$ of ultrapure water were added to $3000 \mu \mathrm{L}$ of the reagent. The samples were then placed in a thermostated water bath set at $95{ }^{\circ} \mathrm{C}$ during $90 \mathrm{~min}$ and, following cooling down, their absorbances were read at a wavelength of $695 \mathrm{~nm}$. The antioxidant activity (A.A., in percentage) can then be calculated using equation 3 .

A.A. $(\%)=\left[\frac{\left(\mathrm{Abs}_{\text {sample }}-\mathrm{Abs}_{\text {blank }}\right)}{\left(\mathrm{Abs}_{\text {ascorbid acid }}-\mathrm{Abs}_{\text {blank }}\right)}\right] 100$

\section{(ii) DPPH method}

The potential for free radical scavenging activity of the crude anthocyanin extract, using the DPPH reagent, was evaluated according to the procedure utilized by Schulz et al. ${ }^{1}$ and Amarowicz et al., ${ }^{27}$ with slight modifications. From a stock solution of crude anthocyanin extract (100 $\mathrm{mg}_{\text {crude anthocyanin extract }} \mathrm{mL}_{\text {ultrapure water }}^{-1}$ ), dilutions were prepared with concentrations of $1,5,10,15$ and $20 \mathrm{mg}_{\text {crude anthocyanin extract }} \mathrm{mL}_{\text {ultrapure water. }}^{-1}$ To $500 \mu \mathrm{L}$ of each crude anthocyanin extract dilution or ascorbic acid dissolved in ultrapure water $\left(500 \mu \mathrm{g}_{\text {ascorbic acid }} \mathrm{mL}_{\text {ultrapure water }}^{-1}\right.$ ), $3500 \mu \mathrm{L}$ of freshly prepared DPPH radical in a methanol solution $\left(1.0 \times 10^{-4} \mathrm{~mol} \mathrm{~L}^{-1}\right)$ was added and vortexed. After reaction for $30 \mathrm{~min}$ at room temperature $\left(25^{\circ} \mathrm{C}\right)$ in the dark, the decolorizing result of the solution was then assayed spectrophotometrically at $517 \mathrm{~nm}$ and compared with a blank control containing the crude anthocyanin extract solution and pure methanol instead of DPPH. In addition, a blind control containing methanol and ultrapure water instead of crude anthocyanin extract solution $(500 \mu \mathrm{L}$ ultrapure water added to $3500 \mu \mathrm{L}$ of methanol) was also assayed. Calculation of free radical scavenging activity (\%) was then carried out using the equation 4 . The spectrophotometer was zeroed with a mixture of plain ultrapure water $(500 \mu \mathrm{L})$ and methanol $(3500 \mu \mathrm{L})$.

Scavenging activity $(\%)=\left(1-\frac{\mathrm{Abs}_{\text {sample }}}{\mathrm{Abs}_{\text {blind }}}\right) 100$ where scavenging activity refers to the free radical scavenging percentage, $\mathrm{Abs}_{\text {sample }}$ refers to the absorbance of the sample at $517 \mathrm{~nm}$, and $\mathrm{Abs}_{\text {blind }}$ refers to the absorbance of the blind control at $517 \mathrm{~nm}$.

Determination of elemental composition by X-ray fluorescence (EDXRF) analyses

The elemental composition of the crude anthocyanin extract was determined using an X-ray fluorescence spectrophotometer with energy dispersion (EDXRF) from Amptek (Bedford, Massachusetts, USA), which comprised an Ag anode and a $25 \mathrm{~mm}^{2}$ SDD X-ray detector with a resolution of $128 \mathrm{eV}$ at the $\mathrm{MnK} \alpha$ line. The voltage applied to the X-ray tube was of $30 \mathrm{kV}$, current $10 \mu \mathrm{A}$, with $10 \%$ lag time in the detector. For preparing a blank and producing a base line, boric acid tablets were produced using $300 \mathrm{mg}$ boric acid (maintained at $80{ }^{\circ} \mathrm{C}$ in an incubation chamber) in the mold and applying a pressure of $90 \mathrm{~N} \mathrm{~m}^{-2}$ during $10 \mathrm{~min}$. A calibration curve was prepared by producing a physical mixture of potassium chloride, manganese sulfate, alpha-alumina, lead oxide, tribasic calcium phosphate, iron chloride, titanium dioxide, silicon dioxide and boric acid, up to a total mass of $10 \mathrm{~g}$. This initial mixture contained 10000 ppm K, Mn, Al, Pb, Ca, Fe and Ti; 3640 ppm Si; 6399 ppm Se; 5000 ppm P; and 22048 ppm Cl. From this initial mixture, physical mixtures were prepared with concentrations of 2000, 1000, 500, 200 and 100 ppm, for the aforementioned elements diluted in boric acid for obtaining the calibration curves. For preparing the samples, $0.1507 \mathrm{~g}_{\text {crude anthocyanin extract }}$ were grinded and homogenized with boric acid (1:1), resulting in $300 \mathrm{mg}$ tablets. All measurements were carried out using atmospheric air, and the measuring time was set at $300 \mathrm{~s}$ (live time) for each sample. A collimator with an aperture of $1 \mathrm{~mm}$ was used in the exit of the X-ray source.

Tomographic analyses of the jussara fruit via X-ray transmission (XRT)

The tomographic images of the jussara fruit were gathered using a $3^{\text {rd }}$ generation $\mathrm{X}$-ray transmission tomograph. ${ }^{28}$ The whole fruit was placed inside the tomograph chamber, and image slices were gathered using the following configurations of the tomographic system: operating voltage set at $50 \mathrm{kV}$ and electric current of $800 \mu \mathrm{A}$. The technique employed for obtaining the tomographic image involved acquisition of a large number of radiographs of the object (image slices), obtained by measuring the intensity of X-rays transmitted through the jussara fruit, at different angular positions. The fruit was rotated $180^{\circ}$, with angular increments of $0.8^{\circ}$, producing 
225 radiographs (projections) per image, each containing $1024 \times 1024$ pixels with a spatial resolution of $23.75 \mu \mathrm{m}$. The exposure time per projection was $2000 \mathrm{~ms}$. At the outlet of the X-ray source it was utilized an $\mathrm{Al}$ filter with $0.5 \mathrm{~mm}$ thickness. Appropriate mathematical algorithms were then used to reconstruct the three-dimensional (3D) tomographic images of the fruit, through the appropriate composition of bi-dimensional (2D) images. The 3D images possessed $1024 \times 1024 \times 1024$ pixels and the same spatial resolution of the $2 \mathrm{D}$ images, and thus the volume of data generated for the fruit is isotropic with relation to the spatial resolution. Having all the projections (radiographs gathered at each angular position), it was utilized the software NRecon ${ }^{\mathrm{TM}}$ from Bruker (version 1.6.9.4, Kontich, Belgium), which uses the algorithm of Feldkamp et al. ${ }^{29}$ in the process of reconstructing the tomographic images.

UV-Vis spectrophotometric scanning of the crude anthocyanin extract

The spectrophotometric scannings (from 190 to $800 \mathrm{~nm}$ ) of the crude anthocyanin extracts were carried out using quartz cuvettes in a UV-Vis spectrophotometer from Shimadzu (model Multispec-1501, Kyoto, Japan), using citrate-phosphate buffer solutions of the crude anthocyanin extract $\left(10 \mathrm{mg} \mathrm{mL}^{-1}\right)$ at different $\mathrm{pH}$ values (viz. 1.0, 2.0, 5.0, 7.0 and 8.0).

Thin layer chromatographic analyses of the crude anthocyanin extract

The crude anthocyanin extract was analyzed for its pigment and sugar profile via TLC, using ALUGRAM ${ }^{\circledR}$ SIL G/UV ${ }_{254}, 0.20 \mathrm{~mm}$ thick, $20 \times 20 \mathrm{~cm}$, silica gel 60 plates with fluorescent indicator (Macherey-Nagel, Germany). An aqueous solution of crude anthocyanin extract was prepared $\left(100 \mathrm{mg}_{\text {crude anthocyanin extract }} \mathrm{mL}_{\text {ultrapure water }}^{-1}\right)$ and utilized in the analysis. For evaluation of the pigment profile, an eluent mixture of ethyl acetate/formic acid/ acetic acid/ $\mathrm{H}_{2} \mathrm{O}(67.11: 7.38: 7.38: 18.12 \mathrm{v} / \mathrm{v})$ was utilized, ${ }^{30}$ whereas for evaluation of the sugar profile an eluent mixture of 1-propanol/ethyl acetate/ $\mathrm{H}_{2} \mathrm{O}(4: 0.5: 0.5, \mathrm{v} / \mathrm{v} / \mathrm{v})$ was utilized. ${ }^{31}$ Upon elution, revelation of the pigment bands was carried out using, sequentially, $1 \%(\mathrm{~m} / \mathrm{m}) \mathrm{NP}$ (diphenylboric acid 2-aminoethyl ester) in methanol and 5\% (m/m) PEG (polyethylene glycol 4000) in ethanol, followed by observation of the plate under ultraviolet light $(360 \mathrm{~nm})$, whereas for revealing the sugar bands the (dry) TLC plate was simply put on top of a heating plate to allow for caramelization of the sugar bands. The Rf values of all individual standards and sample bands were then calculated and compared.

\section{Results and Discussion}

The extraction yield produced in the present research work was $0.1 \%(\mathrm{~m} / \mathrm{m})$, meaning that a total mass of (dry) crude anthocyanin extract of $12.75 \mathrm{~g}$ could be gathered from $12.75 \mathrm{~kg}$ of whole jussara fruits. A preliminary analysis of the crude anthocyanin extract obtained, in the form of an aqueous solution (using $100 \mathrm{mg}_{\text {crude anthocyanin extract }} \mathrm{mL}_{\text {aqueous solution, }}^{-1}$ led to a refractive index of 1.3340 , corresponding to $0.625^{\circ} \mathrm{Brix}$ or $0.625 \%$ saccharose. This result allowed to establish a low sugar concentration in the crude anthocyanin extract. The crude extract underwent then a full physicochemical characterization via quantification of its content in anthocyanins, total phenolic content, FTIR, XRD, DSC, antimicrobial activity, antioxidant and radical scavenging activities via the molybdenum phosphate and DPPH methods, XRF, XRT, UV-Vis scannings and TLC.

Determination of the total anthocyanin content in the crude extract

The skin color of the jussara fruit changes from red to purple to black during the ripening process, an appearance that can be explained by the accumulation of anthocyanins. The measurement of anthocyanin content is critical for both research and industrial applications. Molar absorptivity (or extinction coefficient) in the solvent of choice is required for accurate measurement of anthocyanin content of crude pigment extracts. ${ }^{12}$ The total monomeric anthocyanin content of the crude extracts was determined spectrophotometrically via the differential $\mathrm{pH}$ method, resulting in an average $(\mathrm{n}=3)$ anthocyanin concentration of $176.45 \pm 11.27 \mathrm{mg}_{\text {anthocyanin }} \mathrm{g}_{\text {crude extract }}^{-1}$ (or $17.645 \%(\mathrm{~m} / \mathrm{m})$ ), or, equivalently, $17.64 \pm 1.13 \mathrm{mg}_{\text {anthocyanin }} 100 \mathrm{~g}_{\text {fresh whole fruit matter }}^{-1}$. The differential $\mathrm{pH}$ method is a rapid and simple spectrophotometric method based on the anthocyanin reversible structural transformation as a function of $\mathrm{pH}$ (dark-red colored oxonium form at $\mathrm{pH} 1.0$ and colorless hemiketal form at $\mathrm{pH} 4.5) .{ }^{18}$ The result obtained in the present research is expressed as equivalents of cyanidin3 -glucoside which, according to several authors, ${ }^{1,19,32}$ is the most common anthocyanin pigment found in nature. The results obtained in the present research effort for the anthocyanin concentration in the crude pigment extracts produced from the fruits of jussara are comparable and of the same order of magnitude as those published by Gouvêa et al. ${ }^{11}$ for extracts produced from freezedried açaí (Euterpe oleracea Mart.), as determined by high performance liquid chromatography (HPLC), and Schulz et al. ${ }^{1}$ for jussara fruits in the first stage of the 
ripening process. However, the content of anthocyanins was estimated in the present research effort by the $\mathrm{pH}-$ differential method which, although being practical, does not allow for quantification of isolated anthocyanins and produce the total anthocyanin content generally expressed in cyanidin-3-glucoside equivalent. In their work, Borges et al..$^{13}$ analyzed extracts of jussara fruit from several locations in Brazil and obtained significant variations in the total monomeric anthocyanin contents, ranging from 14.84 to $409.85 \mathrm{mg}_{\text {anthocyanin }} 100 \mathrm{~g}_{\text {fresh fruit matter }}^{-1}$. Schulz et al. ${ }^{1}$ analyzed the anthocyanin contents of jussara fruits along different stages of the ripening process, and concluded that the total content in monomeric anthocyanins spanned from $18.76 \pm 2.90 \mathrm{mg}_{\text {anthocyanin }} 100 \mathrm{~g}_{\text {fresh fruit matter }}^{-1}$ in the first stage of ripening (stage 1) to $634.26 \pm 195.02 \mathrm{mg}_{\text {anthocyanin }}$ $100 \mathrm{~g}_{\text {fresh fruit matter }}^{-1}$ in the last stage of ripening (stage 6). Our results are comparable with the results produced by Schulz et al..$^{1}$ and Borges et al. ${ }^{13}$ The variation in the levels of anthocyanins in the jussara fruit extracts analyzed by Borges et al. ${ }^{13}$ were partially attributable to differences in the growing conditions, whereas the differences reported by Schulz et al. ${ }^{1}$ were attributed to different ripening stages. Additionally, a large variability at various stages of maturation and for different growing conditions, such as temperature and rainfall, is known to affect the contents of anthocyanin. ${ }^{13}$ Chroma generally decreases during the ripening process due to chlorophyll degradation and being related to the synthesis of anthocyanins, mainly of cyanidin-3-glucoside, which darkens the jussara fruit. ${ }^{1,33}$ A higher incidence of solar radiation on the jussara fruit promotes the synthesis of anthocyanins to a larger extent. The berries located in the outer parts of the jussara palm tree receive more sunlight, whose intensity affects the metabolism and synthesis of flavonoids in general stimulating the accumulation of anthocyanins, ${ }^{13,34,35}$ and indeed this may have a large impact not only on the amount of crude pigment extract that can be produced, but also in its anthocyanin content, making it almost impossible to standardize the crude extracts with respect to their anthocyanin contents. But, notwithstanding this conclusion, crude anthocyanin extracts do have high-added value for food and/or pharmaceutical applications. The high antioxidant activity of the jussara fruits is associated with a high anthocyanin content. ${ }^{36}$ Anthocyanins have been associated with a reduced risk of degenerative disease. Due to the high levels of anthocyanins in these fruits, they could be used as a source of bioactive compounds for the development of high-added value products with health-promoting benefits. ${ }^{37}$ Particularly in the food industry, the total anthocyanin content of the jussara fruit is of great importance, since anthocyanin extracts produced from jussara pulp are applied in foods as natural pigments.

Determination of the total phenolic content in the crude anthocyanin extract

Using the calibration curve (equation 5) produced for the phenolic content expressed as gallic acid equivalents.

$\mathrm{Abs}_{765 \mathrm{~nm}}=0.0011 \times\left[\mathrm{GAE}\left(\mu \mathrm{g} \mathrm{mL} L^{-1}\right)\right]+0.0065$;

$\mathrm{r}^{2}=0.99402$

where Abs refers to the absorbance at $765 \mathrm{~nm}$ and GAE is gallic acid equivalents.

The total phenolic content of the crude anthocyanin extract samples $(\mathrm{n}=3)$ was determined as $1.958 \pm 0.070 \mathrm{mg}_{\mathrm{GAE}} \mathrm{g}_{\text {crude anthocyanin extract }}^{-1}$ (or, equivalently, $0.196 \pm 0.007 \mathrm{mg}_{\mathrm{GAE}} \mathrm{g}_{\text {crude anthocyanin extract }}^{-1}$ ). The results obtained in the present research for the total phenolic content per $100 \mathrm{~g}$ of fresh whole jussara fruit matter are one order of magnitude lower than the results obtained by Borges et al. ${ }^{13}$ As already stated, the stage of ripening combined with the incidence of solar radiation on the jussara palm tree has a high influence in the outcome of the analysis of anthocyanins and flavonoids in general. It has been reported by several authors ${ }^{13,16,35}$ that phenolic compounds are metabolized in response to intense solar radiation, also acting as a defense mechanism against herbivorous insects as well as UV-B radiation, and therefore berry inter-variations are due to the route of formation of these compounds, since their presence differs in each berry. The variability observed in the results obtained for the crude extract produced from the jussara fruits utilized is in clear agreement with the observations by Schulz et al., ${ }^{16}$ Borges et al..$^{13}$ and Tomás-Barberan and Espín. ${ }^{35}$

\section{FTIR analyses}

FTIR analyses allow to identify functional groups, since each functional group absorbs radiation in a characteristic frequency of the infrared spectrum. ${ }^{38}$ The infrared spectra of the crude anthocyanin extract from jussara fruits is displayed in Figure 2.

The crude extract exhibited strong absorption bands belonging to the saturated hydrocarbon groups ( $2926 \mathrm{~cm}^{-1}$, corresponding to a methyl group $\left(\mathrm{C}-\mathrm{H}_{3}\right)$, and $2855 \mathrm{~cm}^{-1}$ corresponding to a methylene group $\left.\left(\mathrm{C}-\mathrm{H}_{2}\right)\right){ }^{39}$ The bands at $1711 \mathrm{~cm}^{-1}$ belong to the stretching vibration of $\mathrm{C}-\mathrm{O}$ and bands at $1072 \mathrm{~cm}^{-1}$ corresponding to bending vibration of $\mathrm{C}-\mathrm{O}-\mathrm{C}$ groups can indicate the presence of carbohydrates. ${ }^{39}$ Characteristic peaks indicative of 


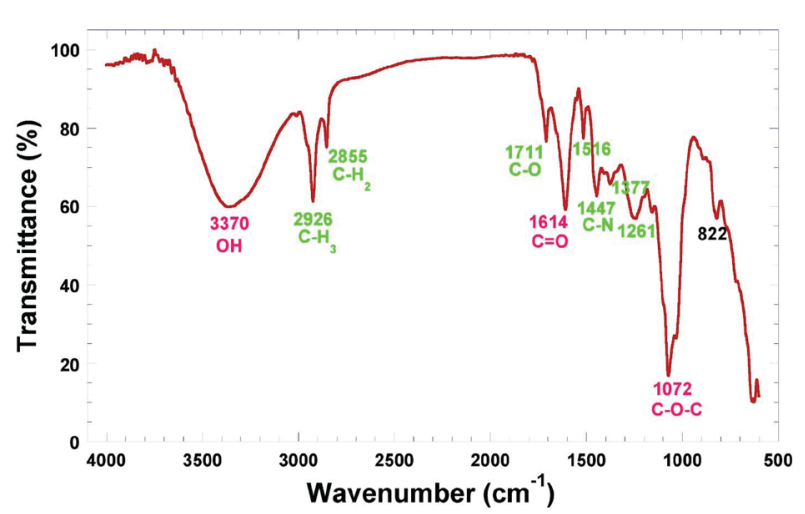

Figure 2. Fourier transform infrared spectrophotometry (FTIR) (ATR) spectrum of the crude anthocyanin extract produced from jussara fruits.

the presence of chlorophyll (observed in $2926 \mathrm{~cm}^{-1}$ corresponding to $\mathrm{C}-\mathrm{H}_{3}$ and $2855 \mathrm{~cm}^{-1}$ corresponding to $\mathrm{C}-\mathrm{H}_{2}$ ) were also identified, probably due to the early ripening stages of the fruits utilized for preparing the crude anthocyanin extract (Figure 2). In addition, bands corresponding to skeletal stretching vibration of the aromatic rings and $=\mathrm{C}-\mathrm{O}-\mathrm{C}$ group of flavonoids $\left(1072,1516\right.$ and $\left.1261 \mathrm{~cm}^{-1}\right)$ were visible. The bands at $1447 \mathrm{~cm}^{-1}$ could also be assigned to $\mathrm{C}-\mathrm{N}$ vibration. ${ }^{40,41}$ Peaks at $1614 \mathrm{~cm}^{-1}$ may also correspond to symmetrical and asymmetrical stretching vibration for the carboxyl ion (COO-) indicating the existence of carboxylic acid, ester, or carbonyl groups. ${ }^{42,43}$ Several absorption bands were identified including those within the region between 800$1750 \mathrm{~cm}^{-1}$, which are categorized as $\mathrm{C}=\mathrm{C}-\mathrm{C}$ aromatic ring stretches, while IR bands in the area from 820 to $760 \mathrm{~cm}^{-1}$ can be attributed to ring vibrations. ${ }^{43}$ The IR region between 1542 to $965 \mathrm{~cm}^{-1}$ is usually referred to as the "fingerprint" region, and various IR bands, including those corresponding to the vibration of the $\mathrm{C}-\mathrm{O}, \mathrm{C}-\mathrm{C}, \mathrm{C}-\mathrm{H}$ and $\mathrm{C}-\mathrm{N}$ bonds, occur in this region. ${ }^{44}$ This area provides important information regarding organic compounds such as sugars, alcohols and organic acids that are probably present in the extract. The distinct absorbance peak in the wavenumber region $3370 \mathrm{~cm}^{-1}$ can also be the result of the absorbance of water. ${ }^{44}$ The $1377 \mathrm{~cm}^{-1}$ absorption band may be attributed to the $\mathrm{O}-\mathrm{H}$ in plane deformation in polyphenols. ${ }^{45}$ On the other hand, the deformation vibration of the carbon-carbon bonds in the phenolic groups adsorb in the region of $1500-1400 \mathrm{~cm}^{-1}{ }^{46}$

\section{XRD analyses}

When the X-ray radiation impacted the powdered crude extract, the lattice spacing of the molecules in the extract behaved as a diffraction grating ${ }^{47}$ and, thus, the diffracted beam possessed different phases since the distance travelled by the beam depends on the plane of reflection. Therefore, the $\mathrm{X}$-ray pattern may be utilized to confirm if the sample being analyzed is either crystalline or amorphous. The diffraction pattern of amorphous samples displays a broad halo with few maxima. Notwithstanding the fact that such halo pattern does not identify the material under scrutiny in a unique fashion, it does confirm, however, that the material is amorphous, which is a critical information needed for characterization. ${ }^{47}$ The results obtained from the XRD analyses performed to the crude anthocyanin extract produced are displayed in Figure 3 in the form of a normalized diffractogram, and allows to observe a generalized amorphous behavior with four peaks of crystallinity.

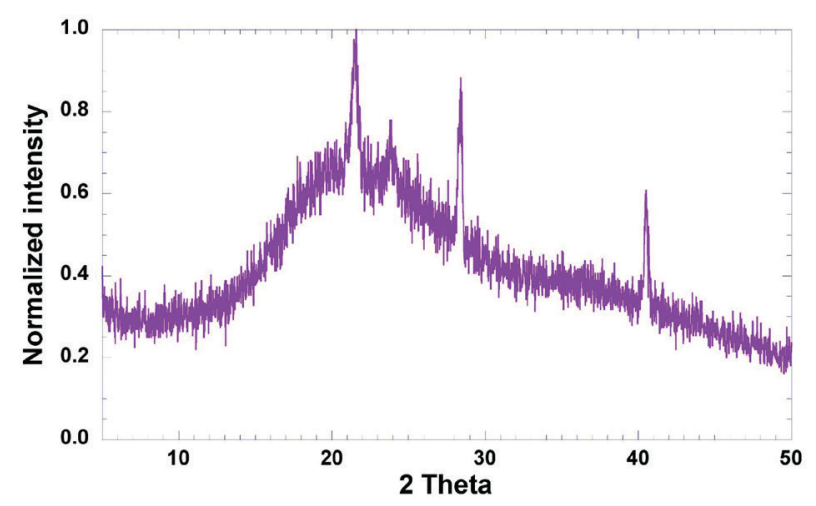

Figure 3. Normalized intensity X-ray diffractogram (XRD) of the crude anthocyanin extract.

The Scherrer equation, ${ }^{48}$ in X-ray diffraction studies, relates the size of sub-micrometer particles, or crystallites, in a solid with the broadening of a peak in a diffraction pattern. It is used in the size determination of particles of crystals in the form of powder. XRD studies allow to measure the size, shape and internal stress of small crystalline regions, by using the Scherrer equation (equation 6).

$\tau(\mathrm{nm})=\frac{(\mathrm{K} \times \lambda)}{(\mathrm{FWHM} \times \cos \theta)}$

where $\tau$ (crystallite size) and $\lambda$ (wavelength) have the same unit of measurement (nm), FWHM is the full width at half maximum of the peak in rad, $\mathrm{K}$ is a dimensionless shape factor (0.94), and $\theta$ is half of Bragg angle in rad.

Observing Figure 3, four peaks of crystallinity appear in the X-ray diffractogram of the crude anthocyanin extract at $2 \theta=21^{\circ}, 24^{\circ}, 28.5^{\circ}$ and $40.5^{\circ}$. Taking into consideration that the X-ray wavelength utilized was equal to $1.5418 \AA$ $(0.15418 \mathrm{~nm})$ and converting all angles in degrees to radians, the crystallites detected at the aforementioned $2 \theta$ values possessed the probable sizes of $\tau_{2 \theta=21}=8.45 \mathrm{~nm}$, 
$\tau_{2 \theta=24}=16.98 \mathrm{~nm}, \tau_{2 \theta=28.5}=17.14 \mathrm{~nm}$, and $\tau_{2 \theta=40.5}=17.70 \mathrm{~nm}$. The Scherrer formula is used for the qualitative comparison, and only when crystallites are smaller than $1000 \AA$ in size. The accuracy of the Scherrer crystallite size equation is, however, limited in part by the uncertainty in FWHM, the experimentally deduced pure diffraction broadening. ${ }^{49}$ The Scherrer formula, stating that the integral breadth is inversely proportional to the apparent size, only addresses line broadening that is entirely caused by size effects, ${ }^{50}$ so the results produced by the Scherrer formula should be carefully interpreted. The Scherrer equation produces a number related to the distribution of length of columns composing the specimen under scrutiny, which can be related, under quite strict hypotheses, to the mean domain size of the crystallite. Normalization of intensity in the diffractogram of the crude anthocyanin extract was performed by dividing the intensity values by the maximum intensity value in the diffractogram (see Figure 3), thus allowing a better comparison between the crystallinity peaks in the X-ray diffractogram. The diffractogram of the crude anthocyanin extract exhibited a wide noisy band, with well-defined peaks in the region of $20.00^{\circ} \leq 2 \theta \leq 42.00^{\circ}$. The spectrum was dominated by a broad non-Bragg diffraction pattern. The produced sharp peaks in the diffraction pattern by the scattering of $\mathrm{X}$-rays by crystalline structures serves as a signature for the material that is analyzed. However, broad features in a diffraction pattern, known as non-Bragg features as a result of the absence of coherent scattering from regular and repeating structures as observed in crystals, are produced by an amorphous material ${ }^{51}$ such as the crude anthocyanin extract analyzed. From the position of the peaks in the XRD diffractogram shown in Figure 3, it can be observed that the crystallographic pattern of the crude anthocyanin extract exhibited sharp peaks at $2 \theta=21^{\circ}, 24^{\circ}, 28.5^{\circ}$, and $40.5^{\circ}$. A broad diffraction peak $\left(2 \theta=5-50^{\circ}\right)$ observed in the XRD spectra of the crude anthocyanin extract is showing the dominance of amorphous material in the crude extract.

\section{Thermal analyses via DSC}

Residual moisture is a key parameter for dried biological extracts, since high moisture contents can be correlated with poor stability. The results from DSC analyses performed to the crude anthocyanin extract, recorded under heating mode between 25 and $300{ }^{\circ} \mathrm{C}$, are displayed in Figure 4 . The shallow endothermic peak observed at $53.25{ }^{\circ} \mathrm{C}$ may be considered as the first order transition commonly observed in a broad class of hydrated biopolymers. By analogy with the work of Dandurand et al., ${ }^{52}$ this endothermic event is attributable to the evaporation of bound water molecules. The second major endothermic event is the sharp endothermic peak at $107.14{ }^{\circ} \mathrm{C}$ (with associated melting enthalpy of $228.05 \mathrm{~J} \mathrm{~g}^{-1}$ ), which is in agreement with the results published by Santos et al..$^{53}$ for an anthocyanin extract from jabuticaba fruit skins. The third major endothermic event is the sharp, small, endothermic peak at $148.70^{\circ} \mathrm{C}$, associated to degradation phenomena, which can be considered as a thermal signature of sample carbonization. $^{54}$

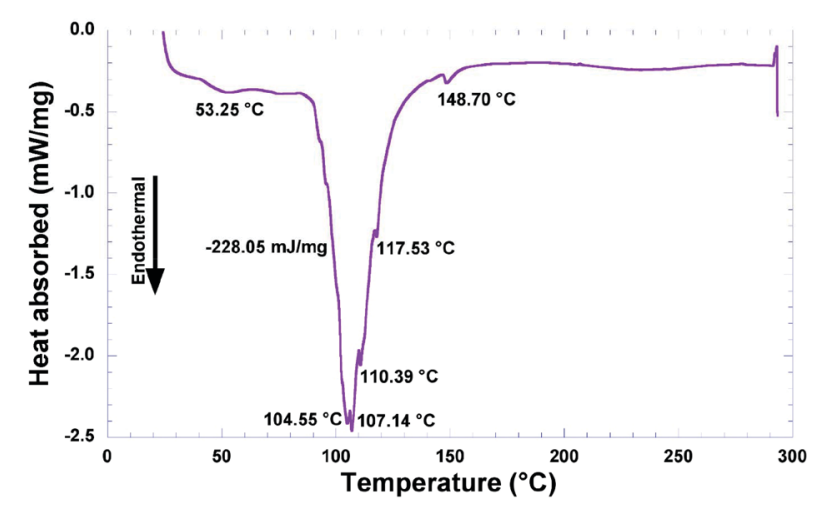

Figure 4. Differential scanning calorimetry (DSC) thermogram of the crude anthocyanin extract.

These results are in close agreement with the data gathered from XRD analyses (Figure 3), allowing to conclude that the crude anthocyanin extract is in fact less amorphous (Figure 3), thus implying a certain degree of crystallinity. This conclusion is ascertained by inspection of the DSC thermogram in Figure 4, where it is possible to observe four very small peaks integrated in the large endothermic peak observed between 100 and $130{ }^{\circ} \mathrm{C}$.

\section{Antimicrobial activity of the crude anthocyanin extract}

Figure 1 displays the results obtained from the antimicrobial activity assays performed to the crude anthocyanin extract.

As can be noticed from inspection of the data displayed in Figure 1, the antimicrobial properties of the crude anthocyanin extract were slightly positive against Staphylococcus aureus (Figure 1b, section 3), but the crude anthocyanin extract did not exert any antibacterial effects against Escherichia coli (Figure 1a, section 3) or Pseudomonas aeruginosa (Figure 1c, section 3). According to Cisowak et al. ${ }^{55}$ the antimicrobial capability of anthocyanins observed in several plant species is due to synergistic mechanism as a function of the presence of (but not limited to) other phenolic compounds and/or organic acids. 
Antioxidant and free radical scavenging activity of the crude anthocyanin extract

The variation in both phenolic compounds and their concentrations promoted by abiotic conditions, as stated above, strongly influences the antioxidant activity of the jussara fruit. ${ }^{13}$ Anthocyanins and other flavonoids do have a high contribution to the antioxidant activity of the crude pigment extracts. Several researchers ${ }^{56}$ demonstrated the strong antioxidant activity of both quercetin and anthocyanins in model systems. The wide diversity of antioxidant polyphenolic compounds present in the jussara fruit ${ }^{12}$ creates a complex biological matrix that contributes to the antioxidant powder of this fruit, but, according to Borges et al. ${ }^{13}$ anthocyanins apparently predominate in the contribution to the antioxidant capacity of jussara. Three to five percent of oxygen escapes during mitochondrial electron transport, without being completely reduced to water. Such incomplete reduction of oxygen leads to the formation of superoxide anion $\left(\mathrm{O}^{2-}\right)$ and eventually to hydrogen peroxide $\left(\mathrm{H}_{2} \mathrm{O}_{2}\right)$ and hydroxyl radical $\left(\mathrm{OH}^{-}\right),{ }^{57,58}$ collectively known as reactive oxygen species (ROS). ${ }^{57}$ There are many scientific reports in the literature correlating the formation of ROS and different major diseases such as cancer, arthritis, and several other disorders..$^{57,59-62}$ Anthocyanins are water-soluble vacuolar pigments that may appear red, purple or blue, depending on the $\mathrm{pH}$. These pigments belong to a parent class of molecules called flavonoids, synthesized via the phenylpropanoid pathway; they are odorless, but flavorful, contributing to taste as a moderately astringent sensation. Anthocyanins occur in all tissues of higher plants, including leaves, stems, roots, flowers, and fruits. Antioxidative properties of blueberries include free radical scavenging, peroxide decomposition, singlet oxygen quenching, synergistic effects, and inhibition of enzymes. ${ }^{13,63-65}$ The free radical scavenging activity of the crude anthocyanin extract was assessed via the DPPH radical method, an assay widely used to evaluate the free radical scavenging ability of natural compounds based on the measurement of the scavenging ability of antioxidant substances towards the stable radical, whereas the antioxidant activity was assayed via the molybdenum phosphate complex assay. The free radical scavenging activity of the crude anthocyanin extract was examined in vitro using the DPPH radical assay utilized by Schulz et al. ${ }^{1}$ and Amarowicz et al. ${ }^{27} \mathrm{DPPH}$ is a stable nitrogen-centered free radical commonly used for assaying the radical scavenging activity of natural extracts. When the stable DPPH radical accepts an electron from the antioxidant compound, the violet color of the DPPH radical is reduced to a yellow-colored diphenylpicrylhydrazine radical, which is measured colorimetrically. The antioxidant activity of the crude anthocyanin extract is assayed by calculating the decrease in absorption. Substances that are able to perform this reaction can be considered as antioxidants and, therefore, radical scavengers. ${ }^{66}$ The results obtained for the DPPH radical scavenging activity of the crude anthocyanin extract are displayed in Figure 5 (green upper curve, left y-axis).

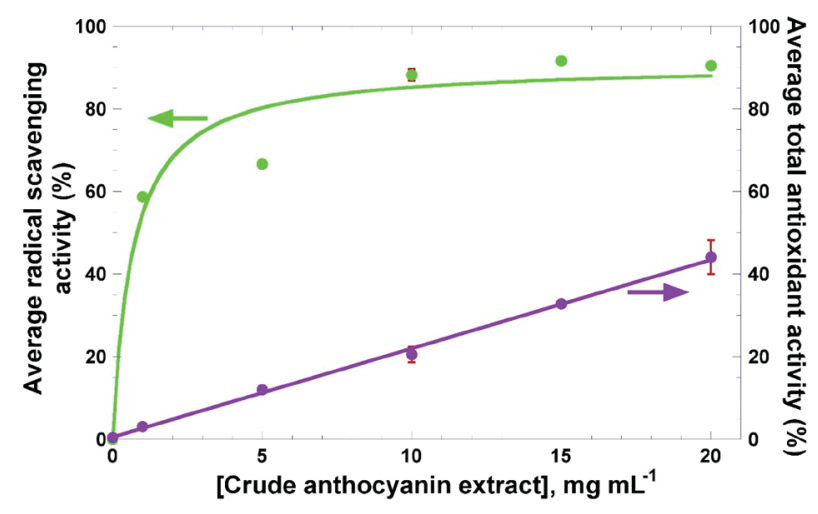

Figure 5. Results from the DPPH radical scavenging activity of the crude anthocyanin extract (green upper curve) and total antioxidant activity via the molybdenum phosphate assay (purple bottom curve), as a function of different mass concentrations of the crude anthocyanin extract $(n=3)$.

The crude anthocyanin extract showed different levels of DPPH radical scavenging activity over the range of concentrations of $0-10 \mathrm{mg} \mathrm{mL}^{-1}$. For higher concentrations, the DPPH radical scavenging activity did not vary much, with the radical scavenging activity of the crude anthocyanin extract exhibiting a hyperbolic increase with increasing concentrations of the crude extract, up to an asymptotic value of ca. 90\%. The hyperbolic curve (equation 7) adjusted via non-linear fitting to the data produced a good correlation coefficient (0.9805) and as parameters a maximum radical scavenging activity $\left(\mathrm{RSA}_{\max }\right)$ of $90.89 \pm 5.28 \%$ and an extract concentration that produces $\mathrm{RSA}_{\max } / 2(\mathrm{~K})$ equal to $0.665 \pm 0.279 \mathrm{mg}_{\text {crude anthocyanin extract }} \mathrm{mL}^{-1}$.

$\operatorname{RSA}(\%)=\frac{\left(\mathrm{RSA}_{\max } \times \text { crude anthocyanin extract }\left(\mathrm{mg} \mathrm{mL}^{-1}\right)\right)}{\left(\mathrm{K}+\text { crude anthocyanin extract }\left(\mathrm{mg} \mathrm{mL}^{-1}\right)\right)}$

where RSA is the radical scavenging activity and $\mathrm{K}$ is a constant with concentration units.

Ascorbic acid was used as antioxidant standard at a concentration of $0.5 \mathrm{mg} \mathrm{mL}^{-1}$ and its free radical scavenging power was found to be $94.2 \pm 0.1 \%(\mathrm{n}=3)$. Hence, the results obtained in the present research effort suggest that the crude anthocyanin extract produced is capable of scavenging the free radicals (although at different extensions) and prevent the initiation of free radicals by 


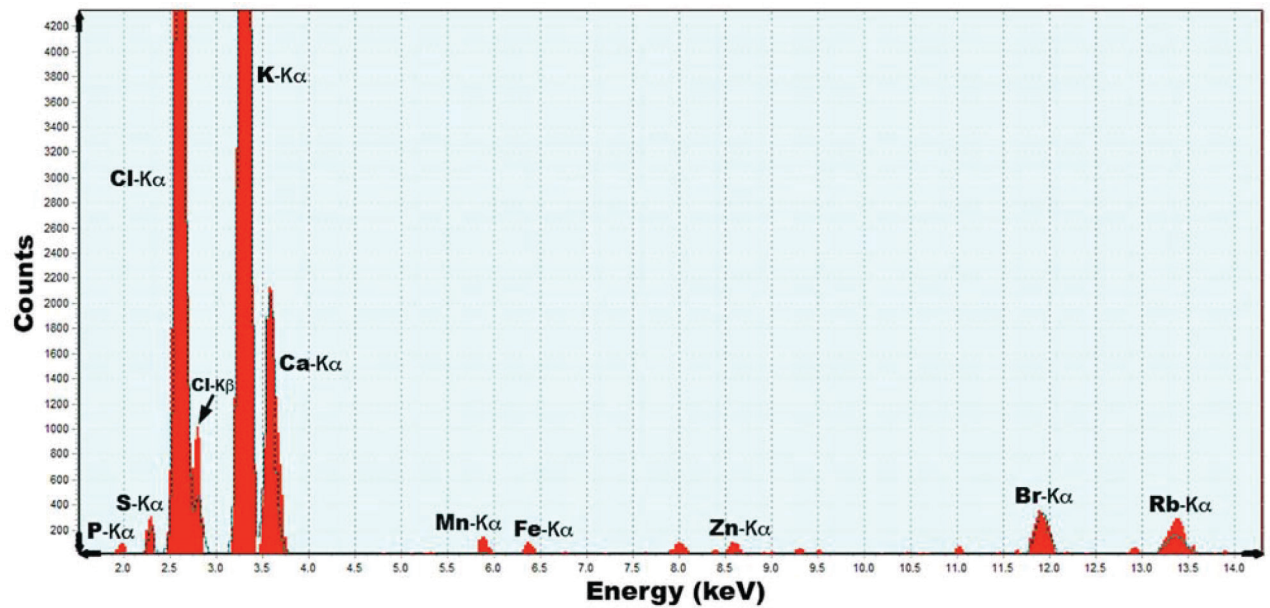

Figure 6. Energy-dispersion X-ray fluorescence (EDXRF) spectrum obtained by EDXRF analysis performed to the crude anthocyanin extract. The y-axis represents the number of characteristic X-ray counts that reached the detector, while the X-axis represents the energy of the characteristic X-rays.

stabilizing them to participate in any deleterious reactions. The total phenolic content of the crude anthocyanin extract showed concentration dependent scavenging of DPPH radical, which may be attributed to its hydrogen donating ability. ${ }^{67}$ When assaying the total antioxidant activity of the crude anthocyanin extract via the molybdenum phosphate complex (a quantitative method to evaluate water-soluble and fat-soluble antioxidant capacity, i.e., the total antioxidant capacity), ${ }^{68}$ the average total antioxidant activity (AA, in percentage) displayed a linear increase (equation 8) with increasing mass concentrations of the crude extract (Figure 5, purple bottom curve, right y-axis), although to a lower extent when comparing with the radical scavenging activity assayed via the DPPH method.

$\mathrm{AA}(\%)=2.144 \times$ crude anthocyanin extract $\left(\mathrm{mg} \mathrm{mL}^{-1}\right)+$ $0.589 ; \mathrm{r}=0.9989$

The crude anthocyanin extract showed electrondonating capacity and thus may have acted as a radical chain terminator, transforming reactive free radical species into more stable non-reactive products. ${ }^{69}$ These results are comparable and in close agreement with results published by Kumar et al. ${ }^{70}$ Lima et al. ${ }^{71}$ and Almulaiky et al.$^{67}$ for the total antioxidant activity expressed in ascorbic acid equivalents $(\%)$. However, one should keep in mind that the results of the average antioxidant activity of the crude extract as assayed via the molybdenum phosphate complex were calculated in relation to the antioxidant activity of ascorbic acid (using either 10 or $20 \mathrm{mg}_{\text {ascorbic acid }} \mathrm{mL}^{-1}$ ), considered the standard of antioxidant moieties. At the concentrations of ascorbic acid utilized in these assays, both produced a maximum (100\%) of antioxidant activity (\%). Hence, a maximum average antioxidant activity of ca. $45 \%$ for the crude anthocyanin extract with relation to ascorbic acid is far from being a low antioxidant index, being of the same order of magnitude as the results published by Kumar et al..$^{70}$

\section{XRF analyses}

The elemental composition of the crude anthocyanin extract produced from jussara fruit, a nature-engineered biomaterial structure, is displayed in Figure 6 in the form of an X-ray fluorescence spectra.

Chloride and potassium were found at high concentrations in the crude anthocyanin extract, viz. 8636 and $17250 \mu \mathrm{g} \mathrm{g}_{\text {crude anthocyanin extract, }}^{-1}$, respectively (see Figure 7).

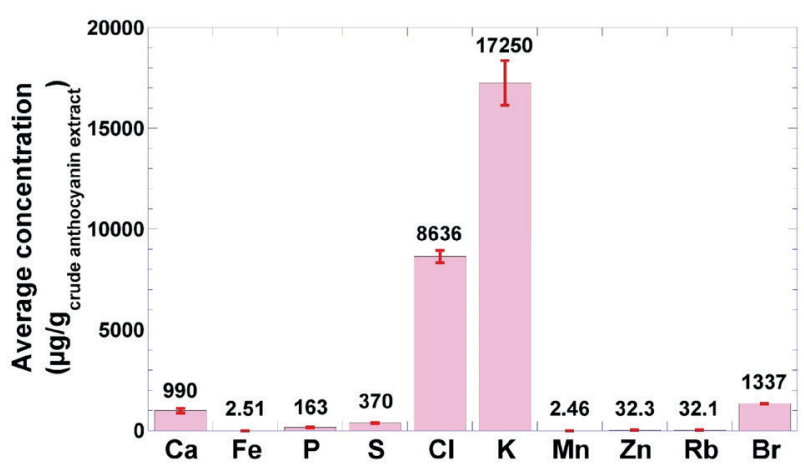

Figure 7. Results from the elemental composition analysis of the crude anthocyanin extract via energy-dispersion X-ray fluorescence (EDXRF).

Besides these two elements, calcium and bromine also appeared in relatively high concentrations (990 and $1337 \mu \mathrm{g} \mathrm{g} \mathrm{g}_{\text {crude anthocyanin extract }}^{-1}$, respectively). Other elements present in trace amounts in the crude anthocyanin extract were iron, phosphorus, sulfur, manganese, zinc and rubidium (see Figures 6 and 7). The mineral contents in the crude anthocyanin extract produced in the present research 
effort were similar to those reported by Inada et al. ${ }^{72}$ namely calcium (1.55x higher in our crude extract) and sulfur (1.38 $\times$ higher in our crude extract), with the exception of potassium $(4.78 \times$ higher in our crude extract), manganese $(11.38 \times$ lower in our crude extract), zinc $(5.38 \times$ higher in our crude extract), iron $(6.65 \times$ lower in our crude extract), and phosphorus $(4.25 \times$ lower in our crude extract). In our crude anthocyanin extract, chlorine, bromine and rubidium were detected, but no correspondence was encountered with other studies published in the literature using crude jussara extracts. The EDXRF technique can provide analytical results with an accuracy of a few parts per million ( $\left.\mu \mathrm{g} \mathrm{g}^{-1}\right)$ and can be used to quantify chemical elements present in a given sample as long as they have an atomic number from element manganese until fermium $(Z=100)$. The results were analyzed both qualitatively and quantitatively. Figure 6 shows the typical X-ray fluorescence spectrum of the crude anthocyanin extract. The major chemical elements found are pinpointed in Figure 6 and quantified in Figure 7. The measured spectra were analyzed with the XRS-FPTM software package provided by Amptek Inc., taking into account both escape and sum peaks, and representing the background with a polynomial function. In the crude extract (see Figures 6 and 7), one found a large amount of chloride, potassium and calcium, and trace amounts of sulfur, iron, phosphorus, manganese, zinc and rubidium. The mineral contents in fruits are very dependent on the soil, fertilization, climatic conditions and cultivar. There is a direct correlation between the mineral nutrients and quality indexes of the fruits such as contents of soluble solids, acidity, $\mathrm{pH}$, fruit firmness, among others. This way the chemical characteristics combined with the nutritional characteristics can be proposed as an excellent tool to check the quality, nutritional value and indicate possibilities of industry applications of the fruits. ${ }^{73}$

\section{XRT analyses}

The jussara palm produces a round fruit, also known as jussara, containing one light brown seed that accounts for ca. $90 \%$ of the fruit diameter (1 to $2 \mathrm{~cm}$ ) and up to $90 \%$ of its weight $0.7-1.9 \mathrm{~g}$. The seeds are covered with a shiny black skin. The jussara fruit analyzed exhibited an external diameter of $11566.35 \pm 167.94 \mu \mathrm{m}$. Anthocyanins are found in the cell vacuole, mostly in flowers and fruits, but also in leaves, stems, and roots. In these plant parts, they are found predominantly in the outer cell layers such as the epidermis and peripheral mesophyll cells. ${ }^{74,75}$ From the tomographic analyses via X-ray transmission performed to the whole jussara fruit (Figure 8), it can be observed that the peel of the fruit (thickness of $700.63 \pm 23.75 \mu \mathrm{m}$ ) is constituted by two concentric layers encasing an inner chamber with a thickness of $107.70 \pm 66.91 \mu \mathrm{m}$.

The skin of the fruit is where anthocyanins are mostly located. The peel, due to its higher atomic density, absorbs more radiation, which makes it in greater evidence as highlighted in the tomographic images displayed in Figure 8, whereas void spaces appear in black scattered all over the fruit's pulp. The inner chamber encased between the two concentric layers constituting the fruit's peel appears in purple. A comparative porosity analysis of the jussara fruit peel can be found in Table 1 .

Anisotropy is the property of being directionally dependent, as opposed to isotropy, implying identical properties in all directions. Anisotropy can thus be defined as a difference, when measured along different axes, in a material's physical or mechanical properties (e.g. absorbance). The degree of anisotropy, calculated as degree of anisotropy (equation 9 ) is 0 for total isotropy and 1 for total anisotropy.

Degree of anisotropy $=[1-(\min$ Eigenvalue $/$ max Eigenvalue $)]$

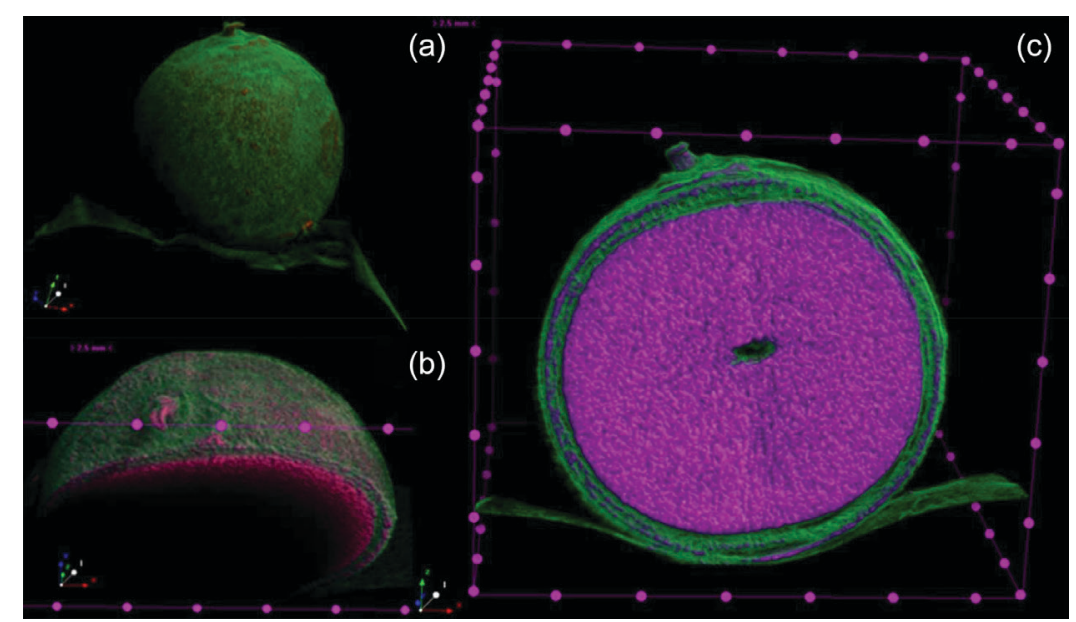

Figure 8. Images obtained by tomographic analyses via X-ray transmission (XRT) of the whole jussara berry, being (a) a tomographic image of the whole fruit; (b) a cross-cut profile image of the berry wall; and (c) a digitally cut image of the berry. 
Table 1. Results obtained from the tomographic analyses via X-ray transmission performed to the jussara fruit peel

\begin{tabular}{|c|c|}
\hline Parameter & Jussara fruit peel \\
\hline Number of layers & 161 \\
\hline Pixel size / $\mu \mathrm{m}$ & 23.750 \\
\hline Total VOI (volume of interest) (TV) / $\mathrm{mm}^{3}$ & 13.555 \\
\hline Object volume $(\mathrm{Obj} . \mathrm{V}) / \mathrm{mm}^{3}$ & 8.299 \\
\hline Percentage of object volume (Obj.V/TV) / \% & 61.228 \\
\hline Total VOI surface $(\mathrm{TS}) / \mathrm{mm}^{2}$ & 77.852 \\
\hline Object surface (Obj.S) / mm² & 167.419 \\
\hline Intersection surface (i.S) $/ \mathrm{mm}^{2}$ & 27.850 \\
\hline Object surface/volume ratio (Obj.S/Obj.V) / mm $\mathrm{mm}^{-1}$ & 20.172 \\
\hline Object surface density (Obj.S/TV) / $\mathrm{mm}^{-1}$ & 12.351 \\
\hline Structure thickness (St.Th) / mm & 0.162 \\
\hline Structure linear density (St.Li.Dn) $/ \mathrm{mm}^{-1}$ & 3.789 \\
\hline Structure separation (St.Sp) / mm & 0.112 \\
\hline Degree of anisotropy (DA) & $2.896(0.655)$ \\
\hline Eigenvalue 1 & 0.0387 \\
\hline Eigenvalue 2 & 0.0759 \\
\hline Eigenvalue 3 & 0.112 \\
\hline Number of closed pores (Po.N(cl)) & 706 \\
\hline Volume of closed pores $(\mathrm{Po} . \mathrm{V}(\mathrm{cl})) / \mathrm{mm}^{3}$ & 0.0376 \\
\hline Surface of closed pores $(\mathrm{Po} . \mathrm{S}(\mathrm{cl})) / \mathrm{mm}^{2}$ & 4.935 \\
\hline Closed porosity (percentage) $(\mathrm{Po}(\mathrm{cl})) / \%$ & 0.451 \\
\hline Volume of open pore space (Po.V(op)) $/ \mathrm{mm}^{3}$ & 5.218 \\
\hline Open porosity (percentage), (Po(op)) / \% & 38.495 \\
\hline Total volume of pore space (Po.V(tot)) $/ \mathrm{mm}^{3}$ & 5.256 \\
\hline Total porosity (percentage) $(\mathrm{Po}(\mathrm{tot})) / \%$ & 38.772 \\
\hline Euler number (Eu.N) & -269 \\
\hline Connectivity (Conn) & 1559 \\
\hline Connectivity density (Conn.Dn) / $\mathrm{mm}^{-3}$ & 115.013 \\
\hline
\end{tabular}

Hence, as can be seen from inspection of the data in Table 1, the degree of anisotropy is 0.655 for the jussara fruit peel, a value that is more close to anisotropy than to isotropy in the aforementioned scale. Being the fruit peel a nature-engineered biomaterial with a complex interwoven structure, this result is easily understandable under the light of the tomographic images displayed in Figure 8. When analyzing the structure of the jussara fruit peel, one finds that it has a low volume of closed pores (viz. $3.76 \times 10^{-2} \mathrm{~mm}^{3}$ ) corresponding to an open porosity of $38.50 \%$, a total porosity of $38.77 \%$, and a total volume of pore space of $5.26 \mathrm{~mm}^{3}$ (see Table 1). These results are in clear agreement with the porosity observed for ripening grapes. ${ }^{76}$ Bindon et al. ${ }^{76}$ observed that fruit skin cell walls became more porous during ripening, which may facilitate the sequestering of tannin as an adsorbed fraction within cell walls. For ethanol extracts, tannin molecular mass increased with advancing ripeness, even when extractable tannin content was constant.

\section{UV-Vis scanning of the crude anthocyanin extract}

The UV-Vis scanning spectra of the crude anthocyanin extract at different $\mathrm{pH}$ values allow to observe the characteristic peak of cyanidin-3-glucoside at acidic $\mathrm{pH}$ (Figure 9).

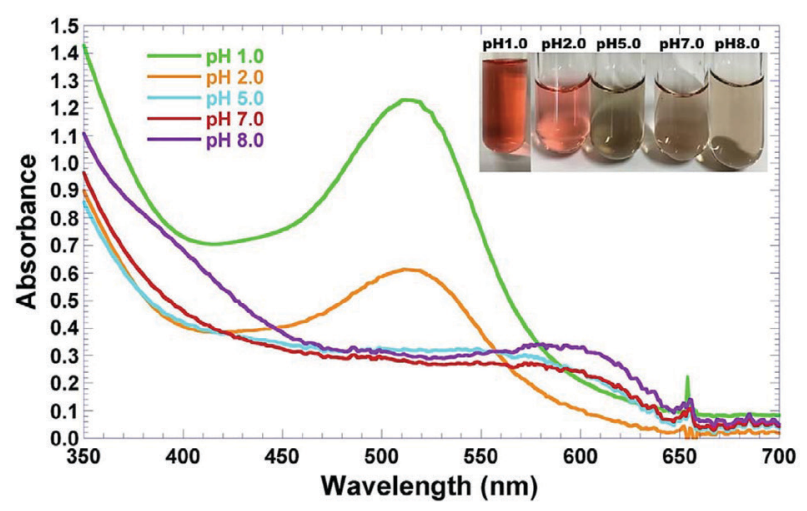

Figure 9. UV-Vis spectral characteristics of the jussara anthocyanins in the crude extract buffered solutions at $\mathrm{pH}$ values 1.0, 2.0, 5.0, 7.0 and 8.0.

Anthocyanins absorb light of selected wavelengths and thus they exhibit colors. ${ }^{3}$ Anthocyanin pigmentation is largely due to the positive charge on the internal ring of the molecule, but this charge is $\mathrm{pH}$ dependent. At a $\mathrm{pH}$ of 1.0, the internal ring carries the positive charge and the molecule is pigmented. However, at $\mathrm{pH}$ values of 5 and higher, the internal ring is hydrated, the positive charge is neutralized and the anthocyanins lose their pigmentation and become colorless. The crude anthocyanin extract UV-Vis absorption spectra are displayed in Figure 9. Clearly, the UV-Vis spectra shows the anthocyanin dependency on the $\mathrm{pH}$. At a pH of 1.0, due to the positive charge on the internal ring, anthocyanins strongly absorb light between 460 and $550 \mathrm{~nm}$ and have a maximum absorption at ca. $520 \mathrm{~nm} .{ }^{3}$ Thus, at very acidic $\mathrm{pH}$, anthocyanins are colored, transmitting violet, short blue and red light to the eye. However, at a $\mathrm{pH}$ value of 5 , due to the loss of the positive charge in the internal ring, anthocyanins do not absorb light in the visible range of the spectrum. At this higher $\mathrm{pH}$ value, they transmit all wavelengths of visible light equally to the eye, and thus are colorless.

Thin layer chromatographic analyses of the crude anthocyanin extracts

The results from the thin layer chromatographic analysis performed to evaluate both the pigment and sugar profile 
of the crude anthocyanin extract are displayed in Figure 10 and Table 2.

\section{Determination of the pigment profile of the crude anthocyanin extract}

The silica molecule constituting the chromatographic layer has hydroxyl groups, which form intermolecular forces with compounds spotted onto the chromatographic plate. Their polarity determines the rate and extent of migration on the stationary phase. The eluting solvents used in this analysis were ethyl acetate, formic acid and acetic acid. More polar molecules will migrate further due to formic acid; the reverse is true for less polar molecules. ${ }^{43}$ The crude extract possesses anthocyanins, which in turn possess attached sugar moieties, making the anthocyanins more polar. On the contrary, aglycones (anthocyanidin), i.e., anthocyanin moieties without sugar molecules attached, may also be present, and these are less polar. Thus, attached sugar moiety increases the polarity of the anthocyanin molecule and, hence, its migration in formic acid. In a formic acid system the aglycone moieties produce spots migrating slower than the anthocyanin moiety spots. There were four pigment fractions formed on the chromatogram from the crude anthocyanin extract (Figure 10a, lane 4). This suggests the existence of four pigments in the crude

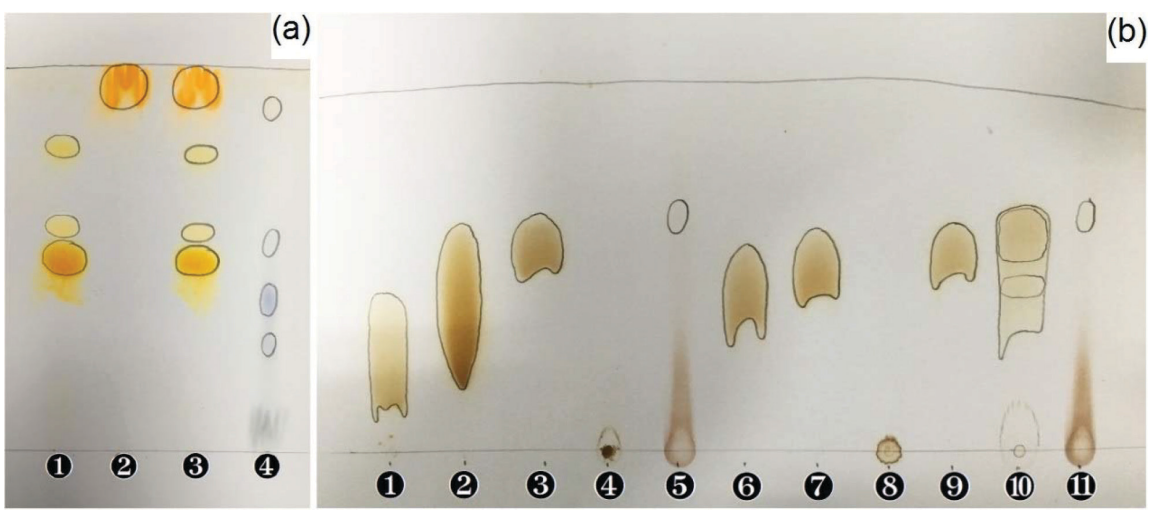

Figure 10. Thin layer chromatography plates of the (a) pigment (1, rutin (quercetin-3-O-rutinoside); 2 , quercetin; 3 , mixture of rutin and quercetin; 4 , crude anthocyanin extract) and (b) sugar (1, lactose; 2 , fructose; 3 , glucose; 4 , starch; 5 , crude anthocyanin extract $\left(100 \mathrm{mg}_{\text {crude anthocyanin extract }} \mathrm{mL}_{\text {ultrapure water }}^{-1}\right.$; 6 , maltose; 7, galactose; 8 , gum arabic; 9 , saccharose; 10 , mixture of sugars $1,2,3,4,6,7,8,9 ; 11$, crude anthocyanin extract $\left.\left(100 \mathrm{mg}_{\text {crude anhocyanin extract }} \mathrm{mL}_{\text {ultrapure water }}^{-1}\right)\right)$ analyses performed to the crude anthocyanin extract.

Table 2. Results obtained from the thin layer chromatographic analyses performed to the crude anthocyanin extract from jussara fruits

\begin{tabular}{|c|c|c|c|c|c|}
\hline \multirow{2}{*}{$\begin{array}{l}\text { Lane } \\
\text { Pigment profile }\end{array}$} & \multirow[t]{2}{*}{ Identification } & \multicolumn{4}{|c|}{ Rf value / cm } \\
\hline & & & & & \\
\hline 1 & rutin & 0.495 & 0.581 & 0.790 & \\
\hline 2 & quercetin & 0.943 & & & \\
\hline 3 & rutin + quercetin & 0.495 & $0.571^{\mathrm{a}}$ & 0.771 & $0.943^{\mathrm{b}}$ \\
\hline 4 & crude anthocyanin extract & 0.276 & 0.390 & $0.543^{\mathrm{a}}$ & $0.895^{\mathrm{b}}$ \\
\hline \multicolumn{6}{|c|}{ Sugar profile } \\
\hline 1 & lactose & 0.276 & & & \\
\hline 2 & fructose & 0.400 & & & \\
\hline 3 & glucose & 0.560 & & & \\
\hline 4 & starch & - & & & \\
\hline 5 & crude anthocyanin extract & $0.634^{\mathrm{a}}$ & & & \\
\hline 6 & maltose & 0.430 & & & \\
\hline 7 & galactose & 0.495 & & & \\
\hline 8 & gum arabic & - & & & \\
\hline 9 & saccharose & 0.540 & & & \\
\hline 10 & mixture of all sugars & 0.449 & $0.602^{\mathrm{c}}$ & & \\
\hline 11 & crude anthocyanin extract & $0.674^{\mathrm{c}}$ & & & \\
\hline
\end{tabular}

${ }^{\mathrm{a}}$ Corresponds to rutin; ${ }^{\mathrm{b}}$ corresponds to quercetin; ${ }^{\mathrm{c}}$ corresponds to glucose. 
extract which are responsible for the observed color in the fruits. It is noteworthy to remember at this time that the fruits utilized to produce the extracts were in the initial stages of ripening and, therefore, traces of chlorophyll were detected in the FTIR analysis of the crude extract. The Rf values of the pigments from the crude extract $(\mathrm{Rf}=0.543$ and 0.895$)$ corresponded to rutin $(\mathrm{Rf}=0.571)$ and quercetin $(\mathrm{Rf}=0.943)$. It can be noted in the formic acid chromatogram that there is a band migrating almost with the solvent front, with an Rf value of 0.943 , corresponding to quercetin.

\section{Determination of the sugar profile of the crude anthocyanin extract}

There are two types of glycosides found in flavonoids, $\mathrm{O}$ - and C-glycosides ${ }^{43}$ The analysis of polysaccharides is difficult for their large molecular weight, complex structures and inert chemical activations. ${ }^{31}$ The sugar moieties integrating the crude anthocyanin extract were detected using silica gel thin layer chromatography. The sugars present in the crude anthocyanin extract were detected by comparing the Rf values of the extract with those of the standard sugars employed. One simple sugar was identified as possible component of the crude anthocyanin extract, as shown in Figure 10b and Table 2. According to the Rf values of the sugar standards and comparing the bands produced by the crude anthocyanin extract, the simple sugar encountered in the crude extract was glucose.

\section{Conclusions}

The extraction method employed to produce a crude anthocyanin extract from the fruits of jussara allowed to produce a crude extract enriched in anthocyanins, whose normalized diffractogram allowed to observe a generalized amorphous behavior with four peaks of crystallinity arising from the presence of very small crystallites. The crude anthocyanin extract exhibited a single sugar, most likely glucose, and a variety of pigments, in close agreement with results published by other researchers. The crude anthocyanin extract exhibited very slight antimicrobial activity against Staphylococcus aureus and both strong DPPH radical scavenging activity and significant total antioxidant activity when compared with ascorbic acid. The results obtained suggest that the crude anthocyanin extract is capable of scavenging free radicals and prevent the initiation of many deleterious oxidation reactions. A large amount of chlorine and potassium was found, together with trace amounts of iron, phosphorus, sulfur, manganese, zinc and rubidium. The crude anthocyanin extract produced was, therefore, found to be suitable for both food and pharmaceutical applications.

\section{Acknowledgments}

Project funding by Fundação de Amparo à Pesquisa do Estado de São Paulo (FAPESP, São Paulo, Brazil; No. 2016/08884-3 (Project PneumoPhageColor) and 2016/12234-4 (Project TransAppIL)) is hereby gratefully acknowledged. Funding by Fundação de Amparo à Pesquisa do Estado de São Paulo (FAPESP No. 2016/16641-3) in the form of an MSc fellowship granted to Liliam Harada is hereby gratefully acknowledged. Funding by the University of Sorocaba (UNISO, Sorocaba, Brazil) for Laura Favaro is hereby gratefully acknowledged. The authors are grateful to Prof Valquíria Yoshida, affiliated with the University of Sorocaba, for her help in preparing the boric acid tablets utilized in the X-ray fluorescence analyses. This work also received support from $\mathrm{CNPq}$, National Council for Scientific and Technological Development, Brazil, in the form of a Research Productivity (PQ) fellowship granted to Victor M. Balcão (No. 308208/2017-0).

\section{References}

1. Schulz, M.; Borges, G. S. C.; Gonzaga, L. V.; Seraglio, S. K. T.; Olivo, I. S.; Azevedo, M. S.; Nehring, P.; Gois, J. S.; Almeida, T. S.; Vitali, L.; Spudeit, D. A.; Micke, G. A.; Borges, D. L. G.; Fett, R.; Food Res. Int. 2015, 77, 125.

2. Cavalcanti, R. N.; Santos, D. T.; Meireles, M. A. A.; Food Res. Int. 2011, 44, 499.

3. Qin, C.; Li, Y.; Niu, W.; Ding, Y.; Zhang, R.; Shang, X.; Czech J. Food Sci. 2010, 28, 117.

4. Miraje, S. Y.; Amlepatil, N. M.; Sahoo, A. K.; Mote, G. V.; J. Innovations Pharm. Biol. Sci. 2015, 2, 218.

5. Fang, J.; Nutrition 2015, 31, 1301.

6. Carvalho, A. G. S.; Machado, M. T. C.; Silva, V. M.; Sartoratto, A.; Rodrigues, R. A. F.; Hubinger, M. D.; Powder Technol. 2016, $294,421$.

7. Garcia-Mendoza, M. P.; Espinosa-Pardo, F. A.; Baseggio, A. M.; Barbero, G. F.; Maróstica Junior, M. R.; Rostagno, M. A.; Martínez, J.; J. Supercrit. Fluids 2017, 119, 9.

8. Cardoso, A. L.; Di Pietro, P. F.; Vieira, F. G. K.; Boaventura, B. C. B.; Liz, S.; Borges, G. S. C.; Fett, R.; Andrade, D. F.; Silva, E. L.; J. Funct. Foods 2015, 17, 152.

9. Vendramini, A. L. A.; Trugo, L. C.; J. Braz. Chem. Soc. 2004, 15,664 .

10. Rodriguez-Amaya, D. B.; Food Sci. 2016, 7, 20.

11. Gouvêa, A. C. M. S.; Araujo, M. C. P.; Schulz, D. F.; Pacheco, S.; Godoy, R. L. O.; Cabral, L. M. C.; Food Sci. Technol. 2012, $32,43$. 
12. Bicudo, M. O. P.; Jó, J.; Oliveira, G. A.; Chaimsohn, F. P.; Sierakowski, M. R.; Freitas, R. A.; Bibani, R. H.; Drying Technol. 2015, 33, 153.

13. Borges, G. S. C.; Vieira, F. G. K.; Copetti, C.; Gonzaga, L. V.; Zambiazi, R. C.; Filho, J.M.; Fett, R.; FoodRes. Int. 2011, 44, 2128.

14. Vieira, G. S.; Cavalcanti, R. N.; Meireles, M. A. A.; Hubinger, M. D.; J. Food Eng. 2013, 119, 196.

15. Peixoto, H.; Roxo, M.; Krstin, S.; Röhrig, T.; Richling, E.; Wink, M.; J. Agric. Food Chem. 2016, 64, 1283.

16. Schulz, M.; Borges, G. S. C.; Gonzaga, L. V.; Costa, A. C. O.; Fett, R.; Food Res. Int. 2016, 89, 14.

17. AOAC; Official Methods of Analysis of the AOAC International, $18^{\text {th }}$ ed.; AOAC International: Maryland, USA, 2005.

18. Lee, J.; Rennaker, C.; Wrolstad, R. E.; Acta Hortic. 2009, 810, 831.

19. Lee, J.; Durst, R. W.; Wrolstad, R. E.; J. AOAC Int. 2005, 88, 1269.

20. Kiralp, S.; Toppare, L.; Process Biochem. 2006, 41, 236.

21. Glasser, C. A.; Vila, M. M. D. C.; Pereira, J. C.; Chaud, M. V.; Oliveira Júnior, J. M.; Tubino, M.; Balcão, V. M.; Drug Dev. Ind. Pharm. 2016, 42, 1990.

22. Bauer, A. W.; Kirby, W. M.; Sherris, J. C.; Turck, M.; Am. J. Clin. Pathol. 1966, 45, 493.

23. Jorgensen, J. H.; Ferraro, M. J.; Clin. Infect. Dis. 2009, 49, 1749.

24. Clinical and Laboratory Standards Institute (CLSI); NCCLS Document M2-A8; Performance Standards for Antimicrobial Disk Susceptibility Tests; Approved Standard, $8^{\text {th }}$ ed.; NCCLS, Wayne, Pennsylvania, USA, 2003.

25. Clinical and Laboratory Standards Institute (CLSI); CLSI Document M100-S21; Performance Standards for Antimicrobial Susceptibility Testing: Twenty-First Informational Supplement; CLSI, Wayne, PA, USA, 2011.

26. Prieto, P.; Pineda, M.; Aguilar, M.; Anal. Biochem. 1999, 269 , 337.

27. Amarowicz, R.; Pegg, R. B.; Rahimi-Moghaddam, P.; Barl, B.; Weil, J. A.; Food Chem. 2004, 84, 551.

28. Oliveira Junior, J. M.; Martins, A. C. G.; de Milito, J. A.; Braz. J. Phys. 2004, 34, 1020.

29. Feldkamp, L. A.; Davis, L. C.; Kress, J. W.; J. Opt. Soc. Am. A 1984, 1, 612.

30. Wagner, H.; Bladt, S.; Zgainski, E. M.; Plant Drug Analysis - A Thin Layer Chromatography Atlas, $2^{\text {nd }}$ ed.; Springer: Berlin, 1996.

31. Skalska-Kamińska, A.; Matysik, G.; Wójciak-Kosior, M.; Donica, H.; Sowa, I.; Ann. Univ. Mariae Curie-Skłodowska DDD 2009, 22, 17. Available at https://pt.scribd.com/ document/371907615/2-indd, accessed in April 2018.

32. Giusti, M. M.; Wrolstad, R. E. In Current Protocols in Food Analytical Chemistry; Wrolstald, R. E., ed.; John Wiley and Sons: New York, 2001, p. 1-13.
33. Brito, E. S.; Araújo, M. C. P.; Alves, R. E.; Carkeet, C. C.; Clevidence, B.; Novotny, J.; J. Agric. Food Chem. 2007, 55, 9389.

34. Terpinc, P.; Abramovic, H.; Food Chem. 2010, 121, 366.

35. Tomás-Barberan, F. A.; Espín, J. C.; J. Sci. Food Agric. 2001, 81,853 .

36. Cunha Jr., L. C.; Teixeira, G. H.; Nardini, V.; Walsh, K. B.; Postharvest Biol. Technol. 2016, 112, 64.

37. Celli, G. B.; Brooks, M. S.; Ghanem, A.; Food Hydrocolloids 2016, 60, 500 .

38. Skoog, D. A.; Holler, F. J.; Crouch, S. R.; Principles of Instrumental Analysis, $6^{\text {th }}$ ed.; Thomson: Canada, 2007.

39. Vasincu, A.; Paulsen, B. S.; Diallo, D.; Vasincu, I.; Aprotosoaie, A. C.; Bild, V.; Charalambous, C.; Constantinou, A. I.; Miron, A.; Gavrilescu, C. M.; Molecules 2014, 19, 19114.

40. Syafinar, R.; Gomesh, N.; Irwanto, M.; Fareq, M.; Irwan, Y. M.; ARPN J. Eng. Appl. Sci. 2015, 10, 6354.

41. Adib, A. M.; Jamaludin, F.; Kiong, L. S.; Hashim, N.; Abdullah, Z.; J. Pharm. Biomed. Anal. 2014, 96, 104.

42. Chang, H.; Kao, M.-J.; Chen, T.-L.; Chen, C.-H.; Cho, K.-C.; Lai, X.-R.; Int. J. Photoenergy 2013, article ID 159502, DOI: 10.1155/2013/159502.

43. Muchuweti, M.; Chikwambi, Z.; Am. J. Food Technol. 2008, 3, 1.

44. Agatonovic-Kustrin, S.; Morton, D. W.; Yusof, A. P. M.; Mod. Chem. Appl. 2013, 1, 110.

45. Ozacar, M.; Soykan, C.; Sengil, I. A.; J. Appl. Polym. Sci. 2006, 102, 786.

46. Nakano, Y.; Takeshita, K.; Tsutsumi, T.; Water Res. 2001, 35, 496.

47. Young, A. L.; Am. Pharm. Rev. 2012. Available at http:// www.americanpharmaceuticalreview.com/FeaturedArticles/38371-Powder-X-ray-Diffraction-and-its-Applicationto-Biotherapeutic-Formulation-Development/, accessed in April 2018.

48. Scherrer, P.; Nachr. Ges. Wiss. Göttingen, Math.-Phys. Klasse 1918, 1918, 98 (in German). Available at https://eudml.org/ doc/59018, accessed in April 2018.

49. Alexander, L.; Klug, H. P.; J. Appl. Phys. 1950, 21, 137.

50. Scardi, P.; Leoni, M.; Delhez, R.; J. Appl. Crystallogr. 2004, 37, 381.

51. Mbonyiryivuze, A.; Omollo, I.; Ngom, B. D.; Mwakikunga, B.; Dhlamini, S. M.; Park, E.; Maaza, M.; Phys. Mater. Chem. 2015, 3, 1 .

52. Dandurand, J.; Samouillan, V.; Lacoste-Ferre, M. H.; Lacabanne, C.; Bochicchio, B.; Pepe, A.; Pathol. Biol. 2014, $62,100$.

53. Santos, D. T.; Albarelli, J. Q.; Beppu, M. M.; Meireles, M. A. A.; Food Res. Int. 2013, 50, 617.

54. Limsitthichaikoon, S.; Saodaeng, K.; Priprem, A.; Damrongrungruang, T.; Int. J. Biol. Biomol. Agric. Food Biotechnol. Eng. 2015, 9, 147. 
55. Cisowak, A.; Dorata, W.; Hendrich, A.; Nat. Prod. Commun. 2011, 6, 149.

56. Hidalgo, M.; Sánchez-Moreno, C.; Pascual-Teresa, S.; Food Chem. 2010, 121, 691.

57. Routray, W.; Orsat, V.; Compr. Rev. Food Sci. Food Saf. 2011, 10, 303 .

58. Kalt, W.; J. Food Sci. 2005, 70, R11.

59. Halliwell, B.; Am. J. Med. 1991, 91, S14.

60. Halliwell, B.; J. Neurochem. 1992, 59, 1609.

61. Halliwell, B.; Gutteridge, J.; Arch. Biochem. Biophys. 1990, 280,1 .

62. Halliwell, B.; Gutteridge, J. M. C.; Guohua, C. A. O.; Cutler, R. G.; Free Radical Biol. Med. 1995, 18, 125.

63. Wang, S. Y.; Chen, C. T.; Sciarappa, W.; Wang, C. Y.; Camp, M. J.; J. Agric. Food Chem. 2008, 56, 5788.

64. Wang, C. Y.; Chen, C. T.; Wang, S. Y.; Food Chem. 2009, 117, 426.

65. Wang, B. C.; He, R.; Li, Z. M.; Food Technol. Biotechnol. 2010 , 48,42 .

66. Dehpour, A. A.; Ebrahimzadeh, M. A.; Nabavi, S. F.; Nabavi, S. M.; Grasas Aceites (Sevilla, Spain) 2009, 60, 405.

67. Almulaiky, Y. Q.; Alshawafi, W. M.; Al-Talhi, H. A.; Zeyadi, M.; Anwar, F.; Al-abbasi, F. A.; Khan, R.; Kumar, V.; Free Radicals Antioxid. 2017, 7, 74.
68. Beghdad, M. C.; Benammar, C.; Bensalah, F.; Sabri, F.-Z.; Belarbi, M.; Chemat, F.; Afr. J. Biotechnol. 2014, 13, 486.

69. Dorman, H. J.; Kosar, M.; Kahlos, K.; Holm, Y.; Hiltunen, R.; J. Agric. Food Chem. 2003, 51, 4563.

70. Kumar, S.; Sandhir, R.; Ojha, S.; BMC Res. Notes 2014, 7, 560.

71. Lima, A. J. B.; Corrêa, A. D.; Sackz, A. A.; Martins, M. P.; Castilho, R. O.; Rev. Bras. Frutic. 2011, 33, 877.

72. Inada, K. O. P.; Oliveira, A. A.; Revorêdo, T. B.; Martins, A. B. N.; Lacerda, E. C. Q.; Freire, A. S.; Braz, B. F.; Santelli, R. E.; Torres, A. G.; Perrone, D.; Monteiro, M. C.; J. Funct. Foods 2015, 17, 422 .

73. Guedes, M. N. S.; Abreu, C. M. P.; Maro, L. A. C.; Pio, R.; Abreu, J. R.; Oliveira, J. O.; Acta Sci., Agron. 2013, 35, 191.

74. Francis, F. J.; Markakis, P. C.; Crit. Rev. Food Sci. Nutr. 2009, 28, 1989.

75. Stafford, H. A.; Plant Sci. 1994, 101, 91.

76. Bindon, K. A.; Madani, S. H.; Pendleton, P.; Smith, P. A.; Kennedy, J. A.; J. Agric. Food Chem. 2014, 62, 1130.

Submitted: February 15, 2018

Published online: April 16, 2018 